\title{
Study the Relationship between the University Student and Teacher using the Principal Component Analysis and Genetic Algorithms
}

\author{
Sahar E. Mahmood \\ sahar_esmaiel@ntu.edu.iq \\ Department of Technical of Computer System, \\ Northern Technical University, Mosul, Iraq.
}

Received on: 08/11/2020

Accepted on: 11/01/2021

\begin{abstract}
Multivariate data analysis is one of the popular techniques, and among them is the Principal Component Analysis, or PCA, is a dimensionality-reduction method which is the process of converting a large number of related variables to a smaller number of unrelated factors, that still contains most of the information in the large set. Therefore, any phenomenon that consist of a large group of variables that are difficult to treat with in their initial form. The process of the interpreting these variables become complex process, so reducing these variables to a smaller is easier to deal with which is the aspiration of every researcher working in the field of principal component analysis. In this research, a multivariate data collection process was carried out which are relates to the nature of education and the relationship between the university student and the teacher, then studying and analyzing by Principal component analysis model, which is a technique used to summarize and condense data through the use of bonding software SPSS, 2020.

Thus, it will be illustrious that this research will fall into a concept Data Mining, and is also abbreviated, and then it is realized using genetic algorithms procedure, in latest version MATLAB 2019B, Application of Genetic Algorithms using simulation software with latest release MATLAB 2019, using the Multiple linear regression equation method.

Multiple linear regression procedure to find the arrangement of independent variables within each factor of the factors obtained, by calculating the weight of the independent variable (Beta). Overall results were obtained for the eigenvalues of the stored correlation matrix, and the study required a Statistical analysis (PCA) method, and by reducing the number of the variables without losing much information about the original variables. The goal is to simplify their understanding. The disclosure of its structure and interpretation, in addition to reaching a set of conclusions that were discussed in detail, In addition to important recommendation.
\end{abstract}

Keywords: University Education ,Principal Component Analysis ,Genetic Algorithms, Data Mining.

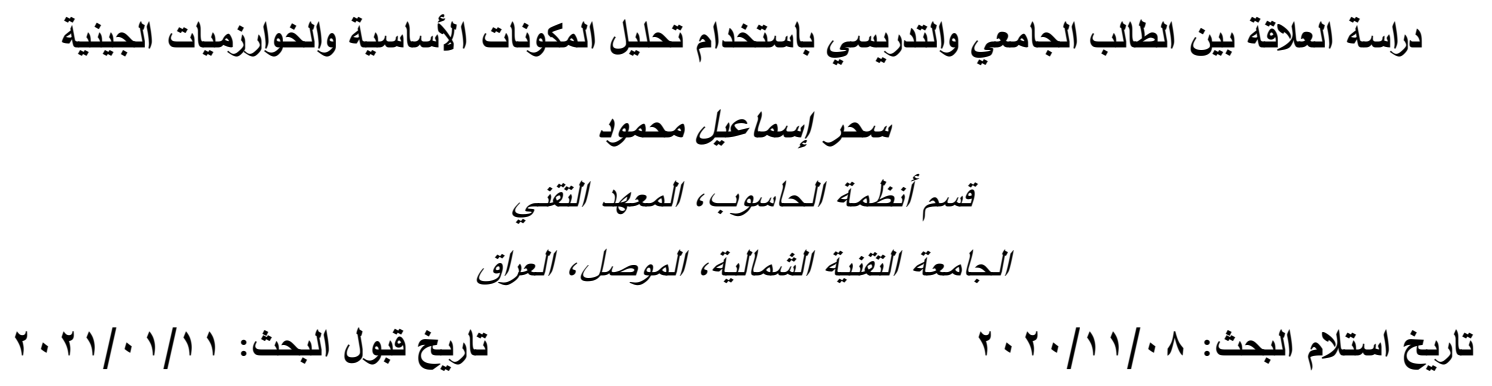


الملخص

يعدُ تحليل البيانات متعددة المتغيرات واحدة من التقانات الثائعة، ومن ضمنها تحليل المكونات الأساسية الذي يقوم بعملية تحويل عدد كبير من المتغيرات المرتبطة إلى عدد أقل من المكونات غير المرتبطة، لذلك فإنَّ العديد من الظواهر التي تتكون من مجموعة كبيره من المتغيرات التي يصعب التعامل معها بصورتها الأولية وتصبح عملية تقسير هذه المتغيرات عملية معقدة؛ لذا فاختزال هذه المتغيرات إلى إعداد أقل يسهل التعامل معها، وهو طموح كل باحث يعمل في مجال تحليل المكونات الرئيسة. تم في هذا البحث عملية جمع بيانات متعددة المتغيرات

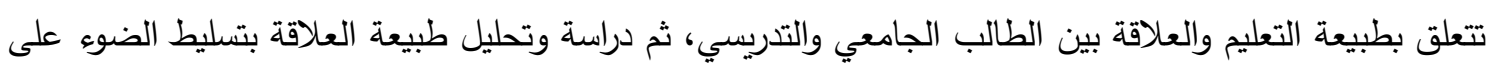

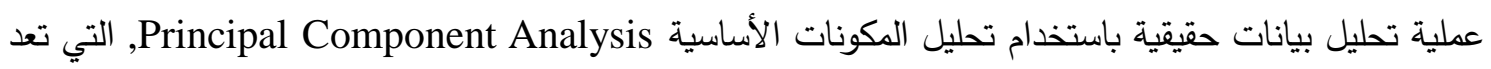
إحدى التقانات المستخدمة في تلخيص البيانات واختصارها، ومن خلال استخدام برنامج الرزم الإحصائية للعلوم

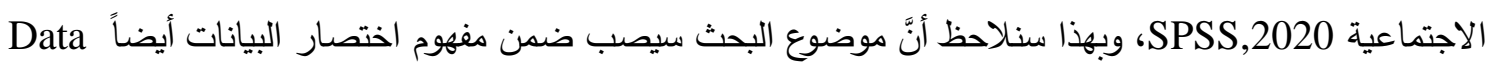

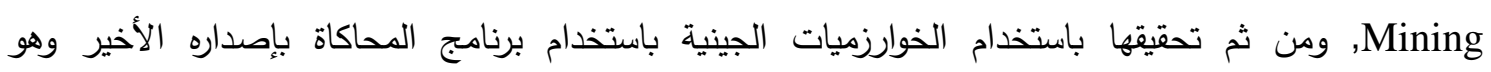

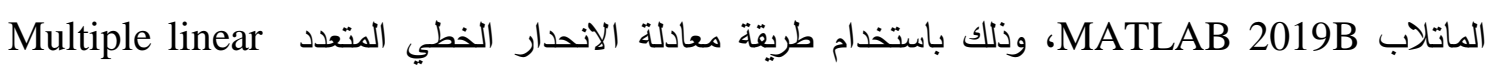
Regression Procedure

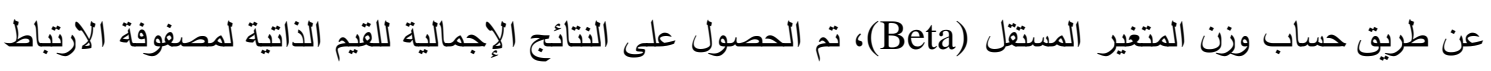
المختزنة، وتطلبت الدراسة إجراء تحليل إحصائي بطريقة (PCA) وبتخفيض عدد المتغير عنيرات دون فقدان معلومات

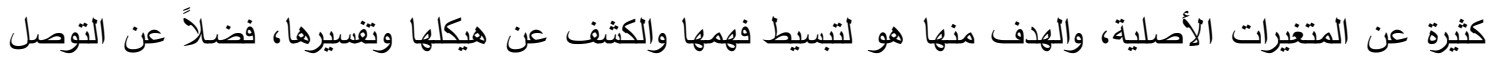
إلى مجموعة من الاستتتاجات التي نوقثت بالتفصيل، فضلاً عن التوصيات المهمة. الكلمات المفتاحية: التعليم الجامعي، تحليل المكونات الأساسية، الخوارزميات الجينية، تتقيب البيانات.

المقدمة Introduction

من المعلوم حالياً أنَّ التطورات العلمة والتكنولوجية وتطوير الأداء الجامعي والاهتمام بخريجي الجامعة يتطلب

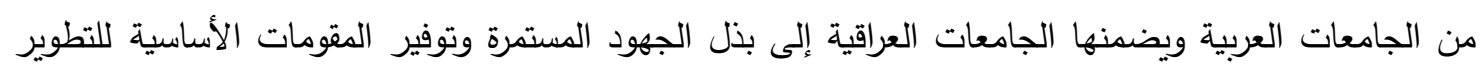
الناجز والمستمر للتعليم العالي [1]؛ إذ تتحمل العبء الأساس في بناء وتركيب العلم والمعرفة والتوهج الحضاري وحيوية الفكر ، سواء للطالب أو التدريسي، ومن أهدافه أتاحة الفرصة لأعداد كبيرة من المواطنين لتحسين مستوياتهم

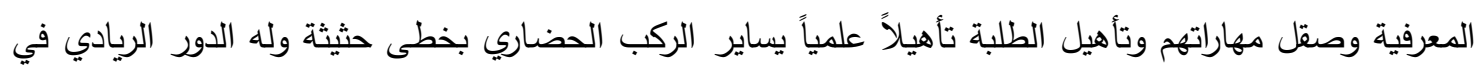
تكوين رأس المال الثقافي وتهيئة الطالب لسوق العمل من خلال تحفيز الطاقات الذهنية له وتحريك مقدرته الابتكارية

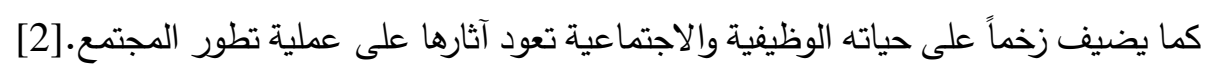

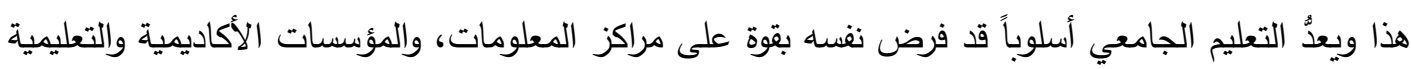

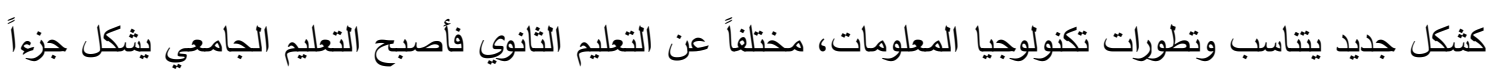

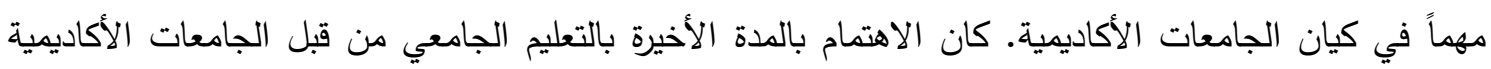

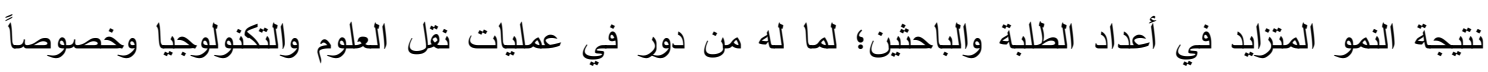

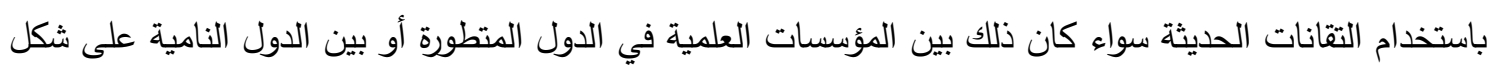
أساليب فنية معينة تساعد هذه الدول النامية على اللحاق بركب الحضارة والتطور الذي يزدهر في كل لحظة في 
أرجاء العالم، ويقصد بالتقانات الحديثة: عملية التعلم او تلقي المعلومة العلمية عن طريق استخدام تقانات الوسائط

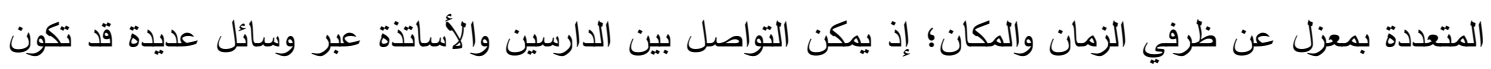
الانترنت، الانترانت، أو التلفاز التفاعلي وتتم عملية التعليم وفق المكان والزمان والكمية والنوعية التي يختارها

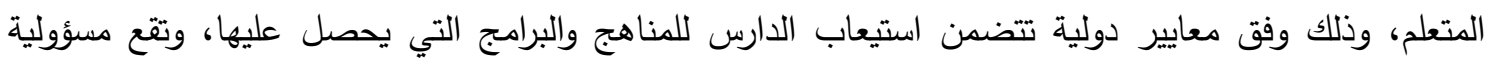
التعلم بصفة أساسية على عاتق المتعلم ذاته، لذلك تعد دراسة العلاقة بين الطالب الجامعي والتدريسي من القضايا

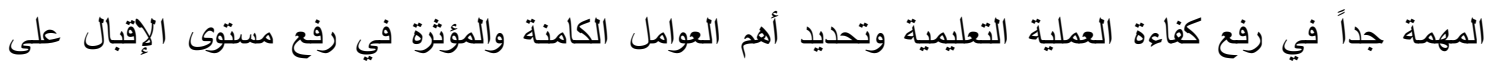

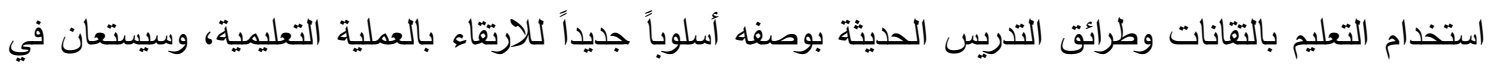
هذا البحث بأسلوب تحليل المكونات الرئيسة الذي يفيد في تحليل العلاقة السببية بكفاءة عالية بين المتغيرات التي درست (أسئلة الاستبيان)، ومن بين الطرائق التي تزيد فاعلية التدريس الجامعي تبرز طريقة تقويم الطلبة للأساتذة؛ بلتئ

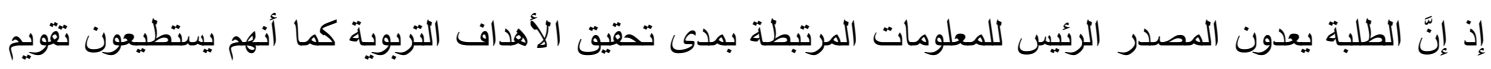

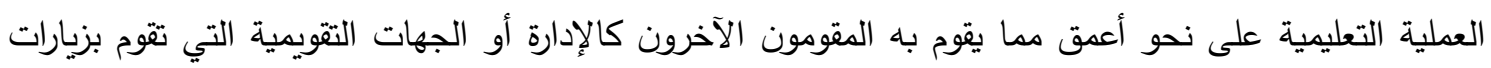

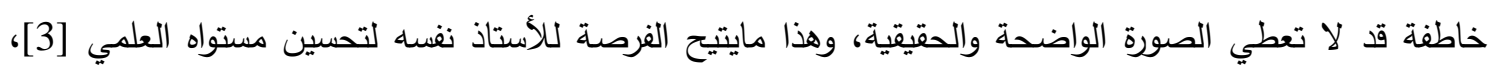

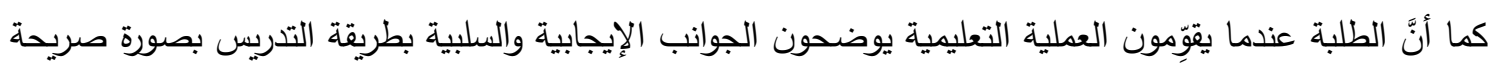
وواضحة ولاسيما إذا كانت تعليقاتهم تكتب بدون ذكر اسم الطالب [4]. ويرى أبو فأرة، (2006) أن إثراك الطلبة

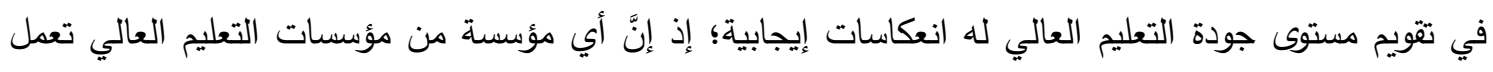
على تحقيق رضا الطلبة من خلال تحسين جودة التعليم العالي في كل بعد من أبعاد الجودة وأهم أبعاد الجودة: الفاعلية والمقبولية والكفاءة والجدارة، وتصميم وتتظيم محتوى الخطط الدراسية وعمليات التعليم والتعلم وآليات تقويم التيم

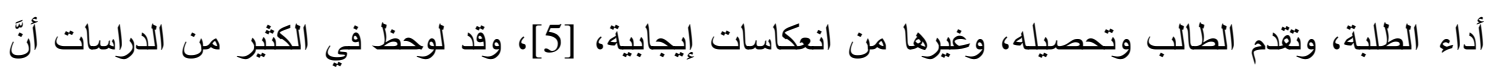
اتجاهات الأساتذة سلبية نحو تقييم الطلبة لفاعلية الممارسة التدريسية مما يجعلهم يشككون في مدى تحقيق التقييم لغرضه [6]. وعموماً لاحظ الثايب (2007) في مراجعته للعديد من الدراسات السابقة في مجال تقويم الطلبة

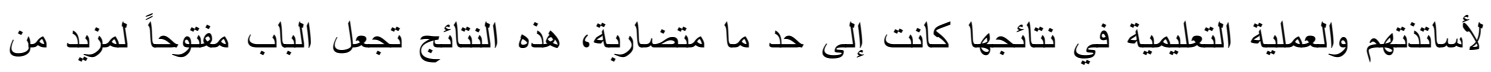
البحوث والدراسات في مجال تقويم فاعلية التدريس الجامعي وكفاءته من وجهة نظر الطلبة [7]، من الناحية النظرية يقصد بكفاءة التدريس مدى تمكن الأستاذ الجامعي في مجال تخصصه ومستوى ثقافته العامة وإلمامه بمهام

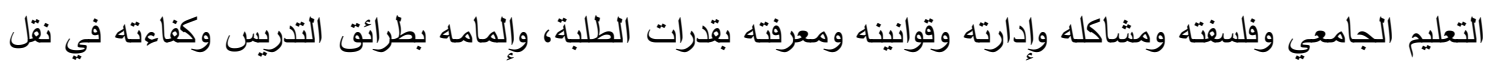

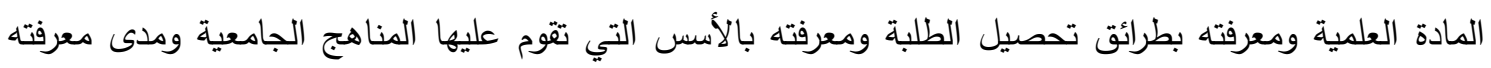

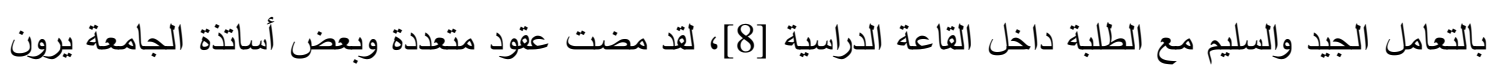
أنَّ تعمق الأستاذ في حقل اختصاصه العلمي ومهارته في بحثه وكثف حقائقه هي ضمانات كافية لإتقان الأستاذ

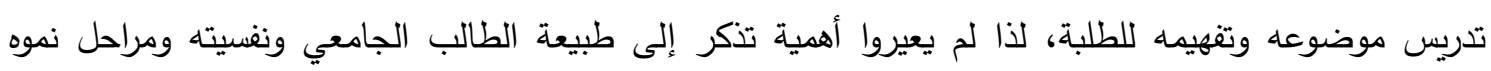

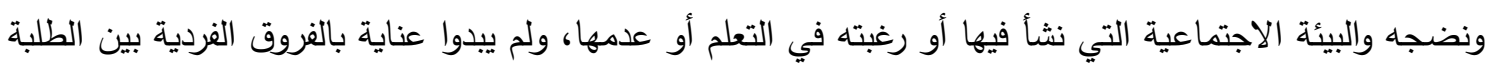

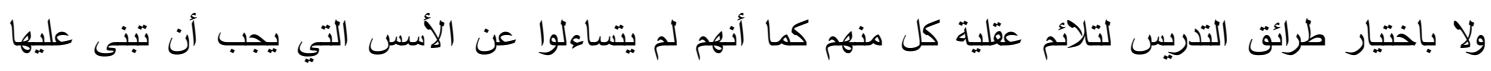

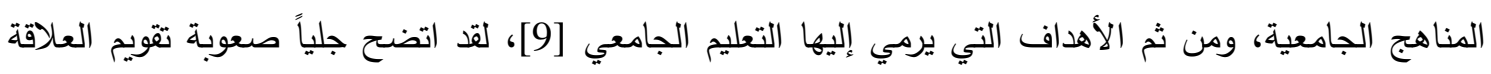

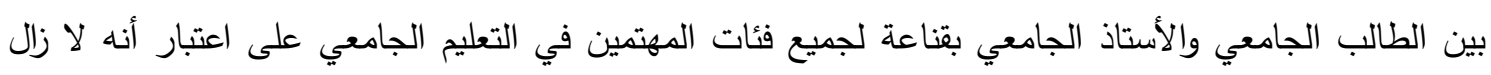

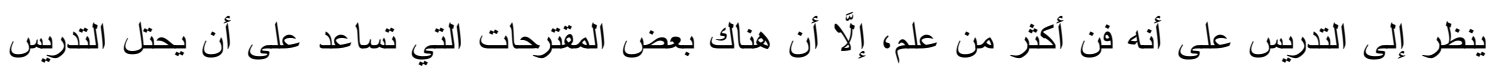


الجامعي مكانته المناسبة، بحيث يصبح إحدى المقومات التي من خلالها يمكن الحكم على نوعية التعليم الجامعي

وفاعليته [8].

لدراسة العوامل التي تكمن وراء طبيعة العلاقات الداخلية (Internal Relationships) أو الارتباطات بين مجموعة المتغيرات المأخوذة لظاهرة دراسة العلاقة بين الطالب الجامعي والتدريسي اختيرت عينة عشوائية بسيطة حجمها 115 طالباً وطالبة من أربعة أقسام في الجامعة التقنية الثمالية، الموصل وهي قسم أنظمة الحاسوب، وقداب وقدم إدارة المواد، وقسم الكهرباء، وقسم التحليلات المرضية. ووزع استبيان استطلاعي عليها تضمن الاستبيان 20 فقرة

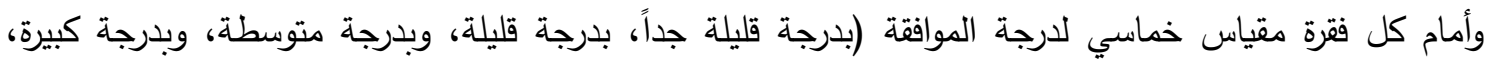

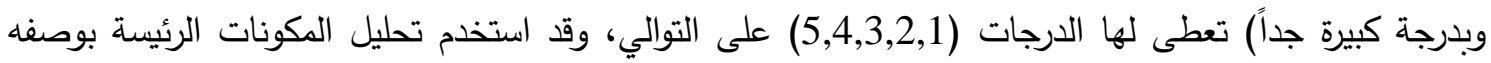

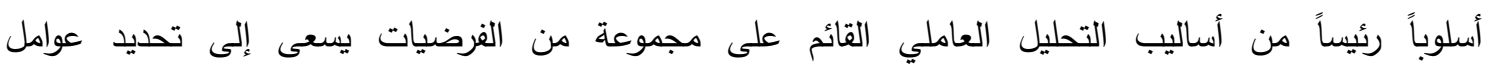
(Hypothetical Factors) لتجميع أكثر عدد من المتغيرات العشوائية التي قد ترتبط بعضها بالبعض الآخر في عدد قليل من المحاور (Axes)

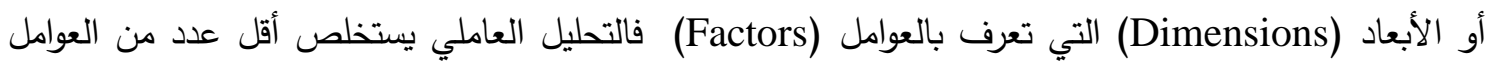

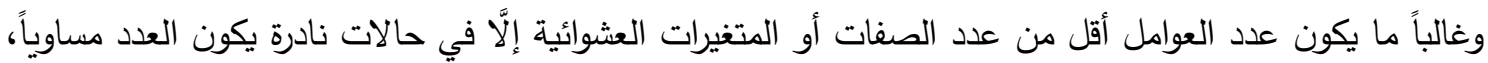

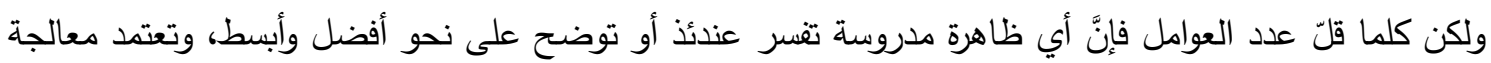

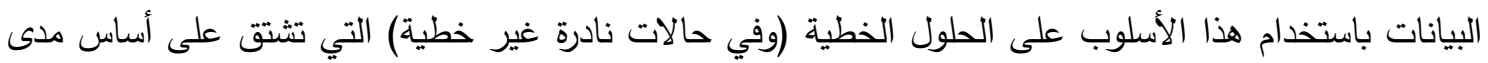
ارتباط المتغيرات فيما بينها، وينحصر مفهوم التحليل العاملي على وفق اتفاق العلماء، بوصفه مجموعة من

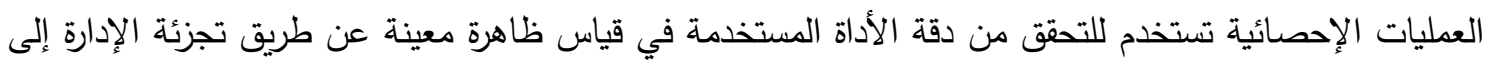
عناصر أو عوامل (Factors) التي تتضمنها ومعرفة وزن كل عامل (Weight) والمتغيرات التي تدخل في نطاقه فئه

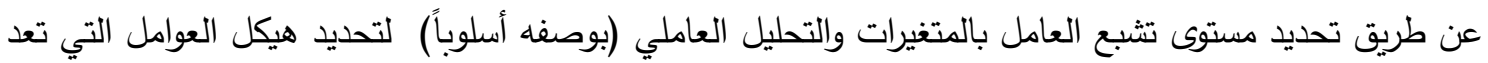

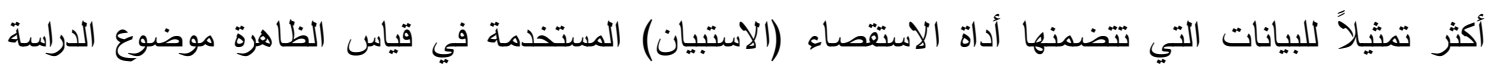

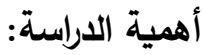

يعد الأستاذ الجامعي من أهم ركائز العملية التعليمية كما أنه المحور الأساسي في تحقيق أهدافها [11]، فهو

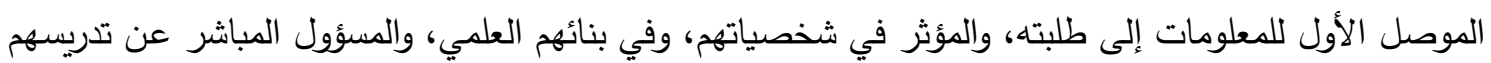
وتطوير قدراتهم في مجال البحث العلمي، فضلاً عما يقوم به من بحوث ودراسات علمية في مجال اختصاصه وهو

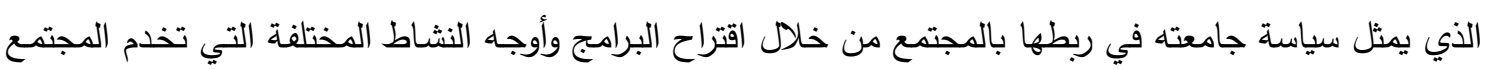

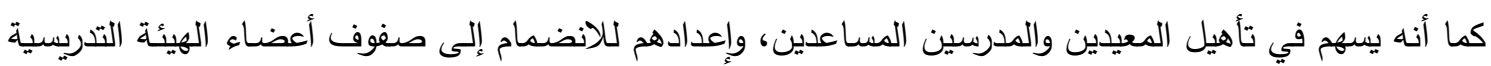

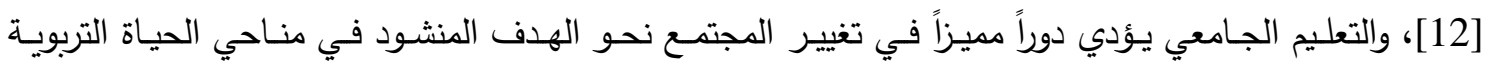
والاجتماعية والاقتصادية والسياسية، ولكي يؤدي هذا الدور المميز لا بد أن تكون مدخلاته ومخرجاته ذات نوعية

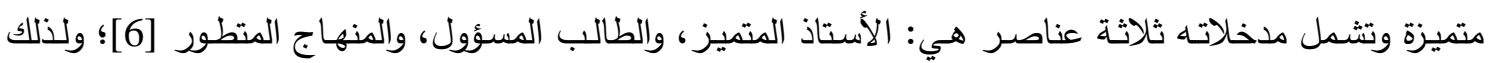
تحرص الجامعات على تتمية وتطوير قدرات ومهارات وكفاءات أعضاء هيئة التدريس من خلال الدورات العلمية واستخدام التقانات الحديثة في التدريس الجامعي بغية توصيل المعلومات إلى الطلبة بكفاءة عالية مما يؤدي إلى مئى 
رفع مستوى التعليم الجامعي[8]، هذا فضلاً عن ضرورة وأهمية قياس آراء الطلبة عن أساتتتهم والممارسة التعليمية

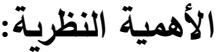

1- تعد واحدة من الاراسات القليلة التي تتاولت تحليل المكونات الرئيسة لتقييم طبيعة العلاقات الخاصـة بالتعليم

2- تتطلق أهمية البحث أيضاً من أهمية تحليل المكونات الرئيسة بحد ذاتها التي تكاد لا تخلو رسالة ماجستير أو دكتوراه في القياس والتقويم من استخدامه.

3- تعريف الباحثين النفسيين والتربوين وطلاب الدراسـات العليا بتحليل (المكونـات الرئيسـة) وطرائقهـ وشروطه وفرضياته بوصفها أسلوباً إحصائياً في مختلف الدراسات العلمية. 4- استخدمت الخوارزميات الجينية لغرض حل معادلات الانحدار الخطي المتعدد لاختصـار البيانات واستبعاد المتغيرات التي لها تأثير قليل في العوامل المستخلصة.

الأهمية التطبيقية:

تساعد في تقديم دراسة تطبيقية حول الأسس المنهجية لتحليل المكونات الرئيسة في ظاهرة الدراسة من خلال

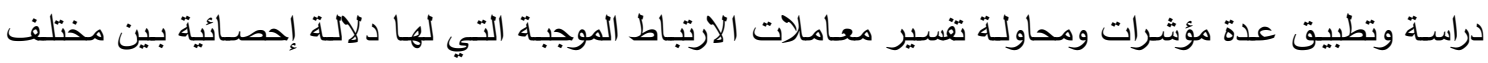

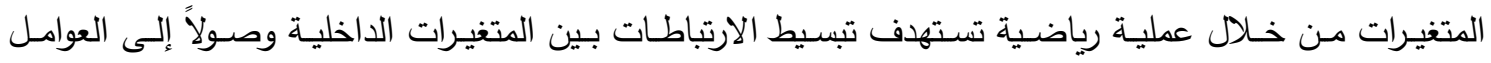
المشتركة التي تصف العلاقة بين هذه المتغيرات التي استخدمت في عملية الدراسة والتقييم وتفسيرها، وتحديد أهمية

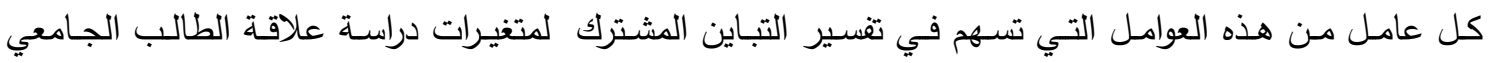
والتدريسي.

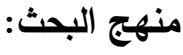

أما منهج البحث فيعتمد على المنهج الوصفي، وذلك بالاستعانة بأجوبة المستبانين وترقيمها وتبويبها التي

تتناول المتغيرات الخاصة باستخدام التعليم الجامعي وتقانة المعلومات وعليه فإن خطة البحث تتضمن:

أولاً: طبيعة العملية التعليمية والحاجة إلى تطوير العلاقة بين الطالب والتدريسي مقارنة بالتعليم الثانوي.

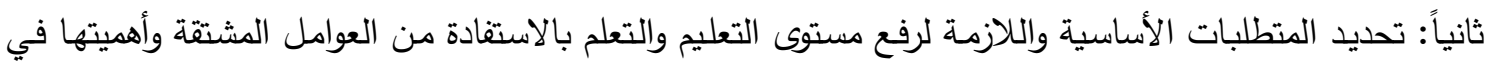
تقسير التباين المشترك لظاهرة دراسة العلاقة بين الطالب والتدريسي في الجامعة التثنية الثمالية/ الموصل.

الاساليب الاحصائية المستخدمة: [14]

اعتمدنا في هذا البحث على التحليل العاملي (Factor Analysis) لإيجاد أهم العوامل المؤثرة في طبيعة العلاقة بين الطالب الجامعي والتدريسي بصورة مختصرة فإنَّ التحليل العاملي يعتمد على احتساب معاملات الارتباط بين المتغيرات، ولأن معامل الارتباط يعطي قياس لقوة ذلك الارتباط بين أي متغيرين، وتعسير معامل الارتباط قد

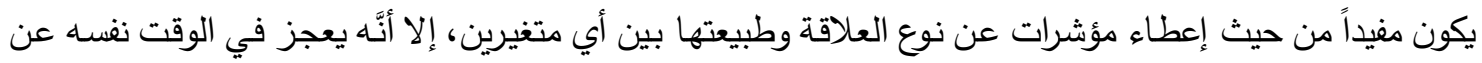
توضيح أي من هذه المتغيرات يمارس تأثيره على نحو مميز عن غيره من المتغيرات الأخرى.

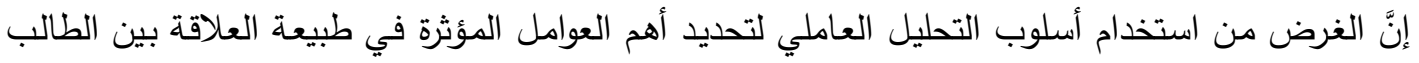
الجامعي والتدريسي على أساس العلاقة القائمة بين هذه المتغيرات وليس على أساس المعاملة المنفصلة لكل متغير ، 
ويفترض التحليل العاملي وجود ارتباط بين مجموعة من المتغيرات نتجت لوجود عوامل مشتركة تؤثر في هذه المتغيرات وأنّ قيم هذه الارتباطات تعود إلى واقع تلك العوامل ومعامل الارتباط بين أي متغيرين يعود إلى طبيعة تثبعها بالعوامل المشتركة ودرجة هذا التشبع ويطلق عليها (Factors) وتعدُّ طريقة العامل الرئيس (Principal Factor) التي تستخدم في هذا البحث من أهم طرائق التحليل العاملي، وهي تطبق بطريقة المحاور الرئيسة

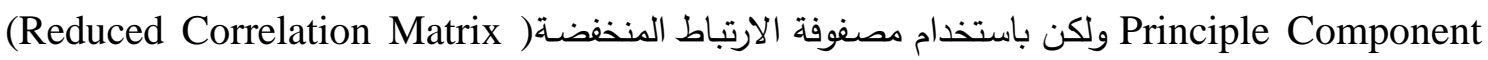
وتأتي الفكرة الأساسية للتحليل بهذه الطريقة لإيجاد نظام جديد للعوامل الرئيسة تكون متعامدة مع محاور موجهات

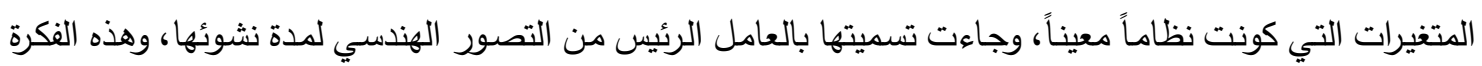
تمثل عدداً من المتغيرات في فراغ عدد محاوره (N)، ومن خلال توزيع حدي المتغيرات توزيعًا طبيعيًا متعدداً فultivariate Normal Distribution ويهدف التحليل العاملي إلى وضع المتغيرات (Xj) بشكل علاقة خطية أو قد تكون غير خطية مع مجموعة من فن النيات العوامل الخطية الفرضية (M) والصيغة الرياضية للدعادلة هي: ولئ $\left.\begin{array}{l}X_{1}=A_{11} F_{1+} A_{12} F_{2} \ldots \ldots . A_{1 m} F_{m}+U_{1} \\ X_{2}=A_{21} F_{1+} A_{22} F_{2} \ldots \ldots \ldots A_{2 m} F_{m}+U_{2} \\ \cdot \\ \dot{X_{j}}=A_{j 1} F_{1+} A_{j 2} F_{2} \ldots \ldots \ldots . A_{j m} F_{m}+U_{j}\end{array}\right\}$

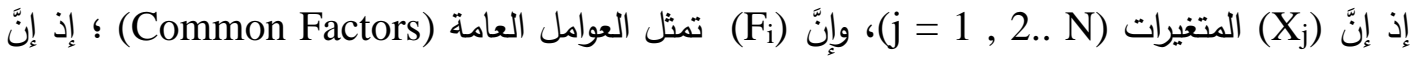
هي عبارة عن عمليات تثترك فيها اثنان من المتغيرات على الأقل بحيث يكون عدد العوامل العامة (i=1,2....M)

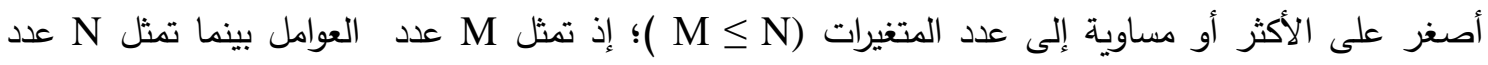

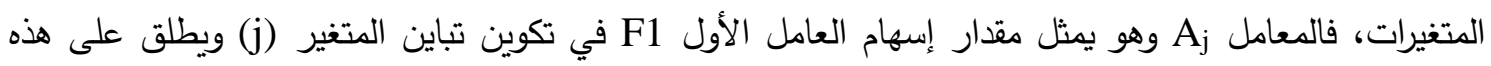
المعاملات بتثبعات العوامل وهذه تثبه معامل الارتباط من حيث حدود قيثل فيمتها واشارتها. F تمثل العوامل المستخلصة من حل أنموذج التحليل العاملي ويتكون كل عامل من مجموعة من المعاملات تمثل تشبع المتغيرات من ذلك العامل، وتعدُّ هذه العوامل عوامل فرضية ترتبط تسميتها بطبيعة المتغيرات التي تكون قيم معاملات ارتباطها مع ذلك المتغير معنوية، ويفسر كل عامل على حدة في ضوه

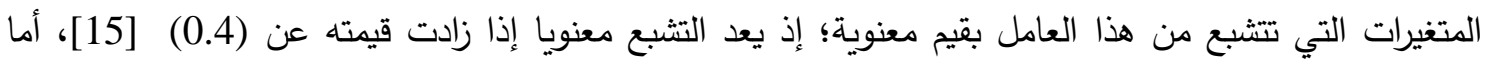
العامل Uj فهو العامل الخاص Unique Factor وهو العامل المثثل لخصوصية المتغير (j) في تكوين الظاهرة، أي ذلك المقدار من قيمة المتغير الذي لا يفسره أي عامل من العوامل المستخلصة الأخرى وإنَّما يرتبط بسلوك مستقل بذلك المتغير [14]، إنَّ تفسير العوامل مهمة في التحليل العاملي لذلك فإنَّ هذه العوامل تشكل موجهات

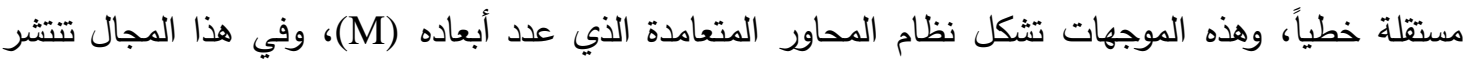
المتغيرات متمثلة بنقاط إحداثيات هذه النقاط، وتثنير إلى تثبعات العوامل، غير أنَّ هذه النقاط لا تتتشر عشوائياً إنَّما

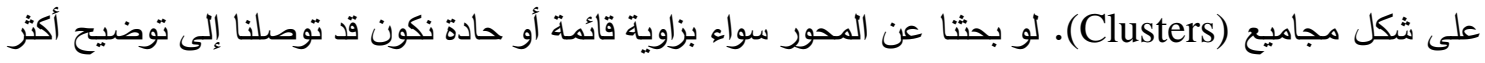
للعوامل وأهم طرائق التدوير هو التدوير المتعامد (Orthogonal Rotation)؛ إذ يهدف التدوير إلى التوصل إلى [16]، أفضل تثبعات للعوامل من خلال تعظيم قيمة التباين المرجع بواسطة مقدار التباين المفنرئ 
الجدول رقم (1) يبين الجذور الكامنة لمصفوفة الارتباط ومجموع مربعات قيم التثبع قبل التدوير وبعده

القيم الأصلية الأولية

مجموع مربعات التحميلات المستخلصة مجموع مربعات التحميلات المستخلصة

المكون قبل التدوير

بعد التدوير

\begin{tabular}{|c|c|c|c|c|c|c|c|c|c|}
\hline & الكلي & التباين \% & التراكمي \% & الكلي & التباين \% & التراكمي\% & الكلي & التباين \% & التراكمي \% \\
\hline 1 & 3.124 & 15.620 & 15.620 & 3.124 & 15.620 & 15.620 & 2.313 & 11.563 & 11.563 \\
\hline 2 & 2.176 & 10.878 & 26.499 & 2.176 & 10.878 & 26.499 & 2.186 & 10.931 & 22.494 \\
\hline 3 & 1.864 & 9.318 & 35.817 & 1.864 & 9.318 & 35.817 & 1.831 & 9.153 & 31.647 \\
\hline 4 & 1.534 & 7.668 & 43.484 & 1.534 & 7.668 & 43.484 & 1.678 & 8.391 & 40.038 \\
\hline 5 & 1.285 & 6.424 & 49.908 & 1.285 & 6.424 & 49.908 & 1.394 & 6.970 & 47.008 \\
\hline 6 & 1.256 & 6.278 & 56.186 & 1.256 & 6.278 & 56.186 & 1.391 & 6.953 & 53.961 \\
\hline 7 & 1.199 & 5.994 & 62.180 & 1.199 & 5.994 & 62.180 & 1.366 & 6.829 & 60.790 \\
\hline 8 & 1.084 & 5.419 & 67.600 & 1.084 & 5.419 & 67.600 & 1.362 & 6.810 & 67.600 \\
\hline 9 & .828 & 4.142 & 71.741 & & & & & & \\
\hline
\end{tabular}

الجدول رقم (2) التوزيع النهائي لككونات عوامل ظاهرة الدراسة موضحاً فيه قيمة الجذر المميز وقيمة التباين الدفسر لكل عامل بعد تدوير المحاور

\begin{tabular}{|c|c|c|c|}
\hline الداخلة في العامل & $\begin{array}{c}\text { نسبة التفسير للعامل في التباين } \\
\text { \% الكلي }\end{array}$ & الجذر المميز للعامل \% & العامل أو المكون الرئيسي \\
\hline 5 & 11.563 & 2.313 & Fac1 \\
\hline 3 & 10.931 & 2.186 & Fac2 \\
\hline 3 & 9.153 & 1.831 & Fac3 \\
\hline 2 & 8.391 & 1.678 & Fac4 \\
\hline 1 & 6.970 & 1.394 & Fac5 \\
\hline 2 & 6.953 & 1.391 & Fac6 \\
\hline 2 & 6.829 & 1.366 & Fac7 \\
\hline 2 & 6.810 & 1.362 & Fac8 \\
\hline 20 & 67.60 & & المجموع \\
\hline
\end{tabular}

ومن خلال استخدام أدوات التحليل الإحصائي يوضح الجدول (3) كميات الثيوع التي تُوصل إليها لمتغيرات العوامل باستخدام تحليل المكونات الأساسية.

الجدول رقم (3) يوضح كميات الثيوع التي تُوصل إليها لمتغيرات العوامل باستخدام تحليل الدكونات الأساسية

\begin{tabular}{|c|c|c|}
\hline 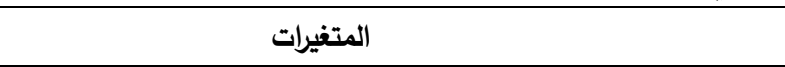 & القيم الأولية & القيم المستخلصة \\
\hline تعامل التدريسيين الجيد مع الطلبة & 1.000 & .644 \\
\hline مراعات التندريسيين لظروف الطلبة والفروق الفردية بينهم أثناء المحاضرة & 1.000 & .744 \\
\hline رفع مستوى التعليم بالعلاقة الإيجابية بين الطرفين & 1.000 & .588 \\
\hline تثجيع الطلبة على التزود بالمستجدات العلمية الحديثة & 1.000 & .651 \\
\hline التشجيع على التتافس العلمي بين الطلبة & 1.000 & .577 \\
\hline مناقثة التدريسي للطلبة حول شكل الامتحانات & 1.000 & .704 \\
\hline تثجيع التدريسي للطلبة على إبداء الآراء & 1.000 & .674 \\
\hline السماح للطلبة بالاعتراض نتائج الامتحانات & 1.000 & .662 \\
\hline قيام التدريسي بتطوير مهاراته تكنولوجيا & 1.000 & .649 \\
\hline استخدام طرائق تدريس لبيان الدور الإيجابي للطلبة & 1.000 & .706 \\
\hline تكليف الطلبة بالواجبات & 1.000 & .751 \\
\hline
\end{tabular}




\begin{tabular}{|c|c|c|}
\hline استخدام أسلوب التثويق في المحاظرة & 1.000 & .757 \\
\hline استخدام الأسئلة الثفوية لعدد من الطلبة دورياً لغرض التقييم & 1.000 & .697 \\
\hline تكليف الطلبة بالتقارير على وفق المجاميع & 1.000 & .686 \\
\hline التركيز على المقدمة التعريفيه لكل محاضرة والأهداف التي تحققها & 1.000 & .722 \\
\hline استخدام التقانات الحديثة في التنريس & 1.000 & .723 \\
\hline استخدام الأفلام الفيديوية معيناً في التدريس & 1.000 & .586 \\
\hline الإجراءات الحازمة لتفادي غش الطلبة & 1.000 & .606 \\
\hline الحرص على التزام الطلبة بالدوام الرسمي & 1.000 & .751 \\
\hline الحرص على شد انتباه الطلبة للمحاضرة وقطع حالة الثرود & 1.000 & .640 \\
\hline
\end{tabular}

وأيضاً باستخدام الأدوات المذكورة سابقاً تم الحصول على العوامل المستخلصة لظاهرة تقييم العلاقة بين الطالب الجامعي والتدريسي باستخدام تحليل المكونات الأساسية الجدول رقم (4). الجدول رقم (4) تثبعات العوامل المؤثرة في ظاهرة الدراسة باستخدام تحليل المكونات الأساسية بعد عملية تدوير المحاور بطريقة (Varimax)

\begin{tabular}{|c|c|c|c|c|c|c|c|c|}
\hline \multirow{2}{*}{ 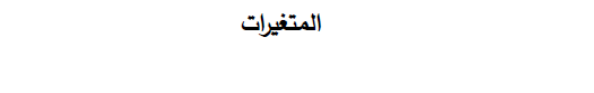 } & \multicolumn{8}{|c|}{ 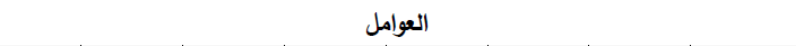 } \\
\hline & 1 & 2 & 3 & 4 & 5 & 6 & 7 & 8 \\
\hline تعامل التدريسيين الجيد مع الطلبة & & & & & & & & -.731 \\
\hline مراعات التدريسيين لظروف الطلبة والثروق الفزدية بينهم أثناء المحاضرة & & & & & & & & .809 \\
\hline رفع مستوى التعليم بالعلاقة الإيجابية بين الطرفين & .705 & & & & & & & \\
\hline تشجيع الطلبة على التزود بالمستجدات العلمية & .578 & & & .521 & & & & \\
\hline التشجيع على التنافس العلمي بين الطلبة & & & .616 & & & & & \\
\hline مناقشة التدريسي للطلبة حول شكل الامتحانات & & & & & & .821 & & \\
\hline تشجيع التدريسي للطلبة على إبداء الآراء & .760 & & & & & & & \\
\hline السماح للطلبة بالاعتراض نتائج الامتحانات & .500 & & & & & .447 & & \\
\hline قيام التتريسي بتطوير مهاراته تكنولوجيا & & .723 & & & & & & \\
\hline استخدام طرائق تدريس لبيان الدور الإيجابي للطلبة & .638 & & & & & & & \\
\hline تكليف الطلبة بالواجبات & & & & & & & .819 & \\
\hline استخدام أسلوب التشويق في المحاظرة & & .842 & & & & & & \\
\hline استخدام الأسئلة الثفوية لعدد من الطلبة دورياً لغرض التيقيم & & & & & .807 & & & \\
\hline تكليف الطلبة بالتقارير على وفق المجاميع & & & & .794 & & & & \\
\hline التركيز على الدقدمة التعريفيه لكل محاضرة والأهداف التي تحققها & & & & .582 & & & & \\
\hline استخدام التقانات الحديثة في التدريس باتجاه التعليم الالكتروني & & .780 & & & & & & \\
\hline استخدام التدريسي للأفلام الفيديوية معيناً في التدريس & & & & & & .422 & & \\
\hline الإجراءات الحازمة لتفادي غش الطلبة & & & & & & & .634 & \\
\hline الحرص على التزام الطلبة بالدوام الرسمي & & & .768 & & & & & \\
\hline الحرص على شد انتباه الطلبة للمحاضرة وقطع حالة الثرود & & & .707 & & & & & \\
\hline
\end{tabular}


الجدول رقم (5) طرائق التدريس الهادفة لرفع المستوى التعليمي وتحفيز الدور الإيجابي للطلبة

\begin{tabular}{|c|c|c|c|c|}
\hline $\begin{array}{c}\text { مقدار الثيوع)(hj²) } \\
\text { (\%) }\end{array}$ & 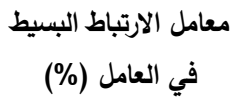 & مقدار التشبع في & المتفيرات الداخلة في العامل & $\begin{array}{l}\text { المتفير) } \\
\text { (رمز }\end{array}$ \\
\hline $67.4 \%$ & $64.9 \%$ & $76.0 \%$ & تثجيع التتريسي للطلبة على ابداء الآراء & $\mathrm{X} 7$ \\
\hline $58.8 \%$ & $65.9 \%$ & $70.5 \%$ & رفع مستوى التعليم بالعلاقة الإيجابية بين الطرفين & $\mathrm{X} 3$ \\
\hline $70.6 \%$ & $53.0 \%$ & $63.8 \%$ & استخدام طرائق التدريس لبيان الدور الإيجابي للطلبة & $\mathrm{X} 10$ \\
\hline $65.1 \%$ & $55.7 \%$ & $57.8 \%$ & تثجيع الطلبة على التزود بالمستجدات العلمية الحديثة & $\mathrm{X} 4$ \\
\hline $66.2 \%$ & $45.8 \%$ & $50.0 \%$ & السماح للطلبة بالاعتراض على نتائج الامتحانات & $\mathrm{X} 8$ \\
\hline
\end{tabular}

الجدول رقم (6) التشويق للمحاضرة باستخدام أساليب التقانات الالكترونية الحديثة

\begin{tabular}{|c|c|c|c|c|}
\hline $\begin{array}{l}\text { مقدار الثيوع (hj) }\left(\mathbf{h y}^{2}\right)\end{array}$ & 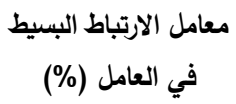 & مقدار التشبع التحميل & المتغيرات الداخلة في العامل & المتغير) \\
\hline $75.7 \%$ & $69.7 \%$ & $84.2 \%$ & استخدام أسلوب التثويق بالمحاضرة & $\mathrm{X} 12$ \\
\hline $72.3 \%$ & $58.7 \%$ & $78.0 \%$ & الباه التعليم الاككتروني التكترونية الحديثة في الترريس & X16 \\
\hline $64.9 \%$ & $53.9 \%$ & $72.3 \%$ & قيام التدريسي بتطوير مهاراته تكنولوجيا & X9 \\
\hline
\end{tabular}

جدول رقم (7) الالتزام بالدوام والحرص على الانتباه والتتافس العلمي

\begin{tabular}{|c|c|c|c|c|}
\hline $\begin{array}{l}\text { مقدار الثيوع (hj) }\left(\text { (hj }^{2}\right)\end{array}$ & معامل الارتباط البسيط & في العامل (\%) مقار التثبع & المتغيرات الداخلة في العامل & 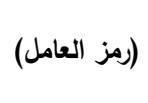 \\
\hline $75.1 \%$ & $72.6 \%$ & $76.8 \%$ & الحرص على التزام الطلبة بالدوام الرسمي & X19 \\
\hline $64.0 \%$ & $67.1 \%$ & $70.7 \%$ & الحرص على شد انتباه الطلبة للدحاضرة وقطع حالة الثرود & $\mathrm{X} 20$ \\
\hline $57.7 \%$ & $56.6 \%$ & $61.6 \%$ & التشجيع على التنافس العلمي بين الطلبة & $\mathrm{X} 5$ \\
\hline
\end{tabular}

الجدول رقم (8) استخدام التقارير لهجاميع الطلبة والمقدمة التعريفية لكل محاضرة والأهداف المطلوب تحقيقها

\begin{tabular}{|c|c|c|c|c|}
\hline $\begin{array}{c}\text { مقدار الثيوع)(hj²) } \\
\text { (h) }\end{array}$ & 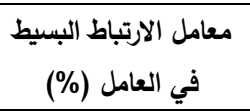 & مقدار التشبع في & المتغيرات الداخلة في العامل & $\begin{array}{l}\text { المتنير) } \\
\end{array}$ \\
\hline $68.8 \%$ & $79.4 \%$ & $79.4 \%$ & تكليف الطلبة بكتابة التقارير على وفق الججاميع & $\mathrm{X} 14$ \\
\hline $72.2 \%$ & $57.0 \%$ & $58.2 \%$ & التركيز على المقدمة التعريفية لكل محاضرة & X15 \\
\hline
\end{tabular}

الجدول رقم (9) استخدام الأسئلة الثفوية لتقييم الطلبة في المحاضرة

\begin{tabular}{|c|c|c|c|c|}
\hline 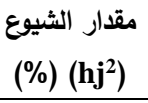 & 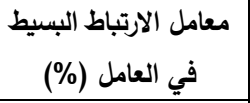 & مقدار التشبع في & المتغيرات الداخلة في العامل & $\begin{array}{l}\text { المتفير) } \\
\end{array}$ \\
\hline $69.7 \%$ & $77.8 \%$ & $80.7 \%$ & استخدام الأسئلة الشفوية لعدد من الطلبة في كل محاضرة & $\mathrm{X} 13$ \\
\hline
\end{tabular}


الجدول رقم (10) مناقثة شكل وطبيعة الاتحانات مع الطلبة

\begin{tabular}{|c|c|c|c|c|}
\hline 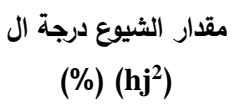 & معامل الارتباط البسيط & في العامل (التشبع) & المتغيرات الداخلة في العامل & $\begin{array}{l}\text { المتفير) } \\
\text { (رمز }\end{array}$ \\
\hline $70.4 \%$ & $83.7 \%$ & $82.1 \%$ & مناقشة التتريسي للطالب حول شكل الامتحانات & $\mathrm{X} 6$ \\
\hline $58.6 \%$ & 42.7 & $42.2 \%$ & استخدام التدريسي الافلام الفيديوية كمعين في التدريس & $\mathrm{X} 17$ \\
\hline
\end{tabular}

الجدول رقم (11) تكليف الطلبة بالواجبات وإجراءات تفادي الغش لدى الطلبة

\begin{tabular}{|c|c|c|c|c|}
\hline $\begin{array}{c}\text { مقدار الثيوع (hj²) } \\
\text { (h) }\end{array}$ & معامل الارتباط البسيط في & $\begin{array}{c}\text { مقدار التثبع في العامل } \\
\text { (\%) }\end{array}$ & المتغيرات الداخلة في العامل & المتفير) \\
\hline $75.1 \%$ & $81.5 \%$ & $81.9 \%$ & تكليف الطلبة بالواجبات & $\mathrm{X} 11$ \\
\hline $60.6 \%$ & $58.9 \%$ & $63.4 \%$ & الإجراءات الحازمة لتفادي غش الطلبة & $\mathrm{X} 18$ \\
\hline
\end{tabular}

جدول رقم (12) التعامل الجيد مع الطلبة ومراعات الفروق الفردية بينهم في المحاضرة

\begin{tabular}{|c|c|c|c|c|}
\hline $\begin{array}{l}\text { مقدار الثيوع (hj²) } \\
\text { (ho) }\end{array}$ & معامل الارتباط البسيط في & مقدار التشبع في & المتغيرات الداخلة في العامل & (رمز لمتغير) \\
\hline $74.4 \%$ & $83.7 \%$ & $80.9 \%$ & 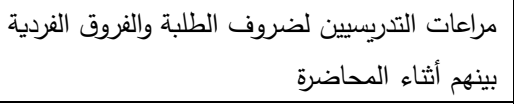 & $\mathrm{X} 2$ \\
\hline $64.4 \%$ & $-61.1 \%$ & $-73.1 \%$ & التعامل الجيد مع الطلبة & $\mathrm{X} 1$ \\
\hline
\end{tabular}

\section{النتائج والمناقشة}

باستخدام برنامج (SPSS) الجزء الخاص بالتحليل العاملي تم الحصول على النتائج الإجمالية للقيم الذاتية

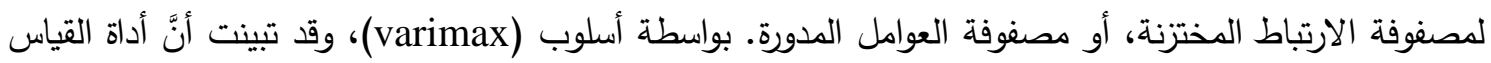

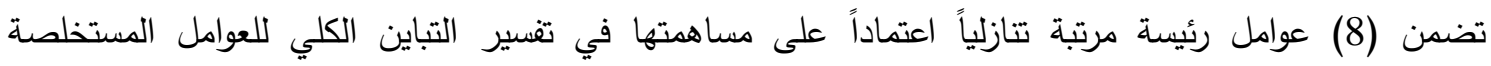
والمساهمة في تقييم طبيعة العلاقة بين الطالب والأستاذ لرفع كفاءة التعليم، وقد التبل اختيرت أساساً على القيم الذاتية

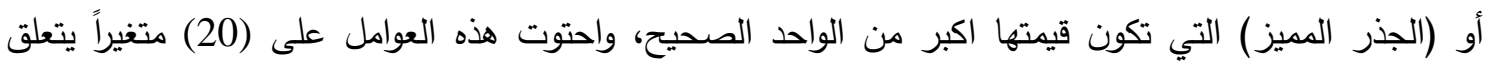

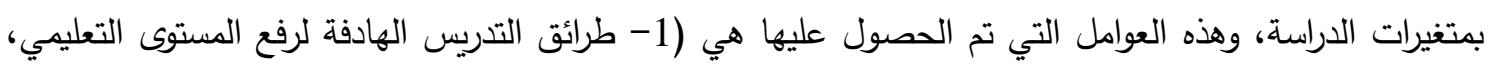

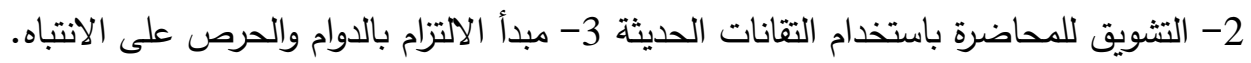
التنافس العلمي ،... الخخ)؛ إذ استطاعت هذه العوامل الثمانية تقسير بما مقداره (67.6) من إجمالي التباين في

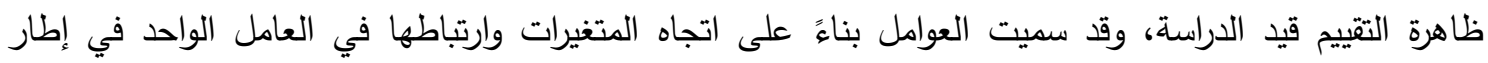

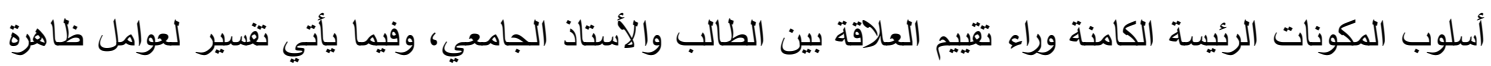
دراسة العلاقة بين الطالب الجامعي والتدريسي.

\section{العامل الأول: طرائق التدريس الهادفة لرفع المستوى التعليمي}

يتمثل هذا العامل بالحرص على اتباع السبل لرفع مستوى العلاقة بين الطالب الجامعي والتدريسي من خلال مناقثة الطلبة وتحديد أهم الآراء التي يبديها لغرض تحديد آلية وطريقة التعامل التعليمي معهم، وكذلك إعطاء دور

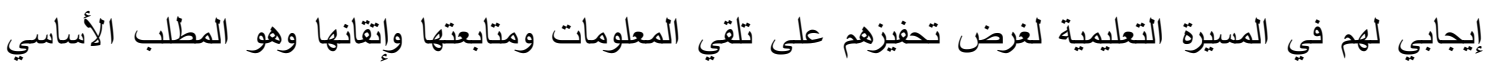
لرفع مستوى التعليم [17]، وقد بلغت نسبة تأثير هذا العامل في تقييم هذه العلاقة بمقدار

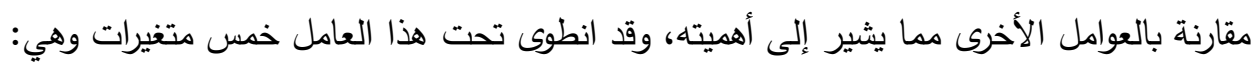


1- تثجيع التدريسي للطلبة على إبداء الآراء 2- رفع مستوى التعليم بالعلاقة الإيجابية بين الطرفين (بينه وبين

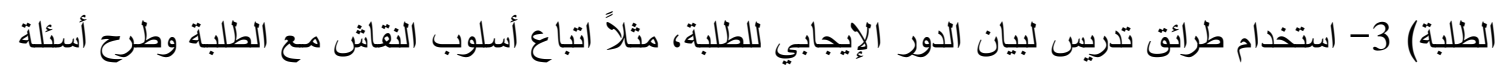

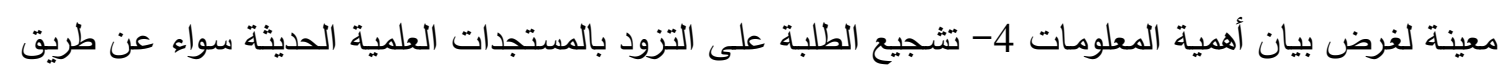

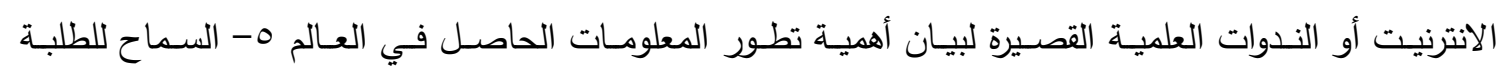

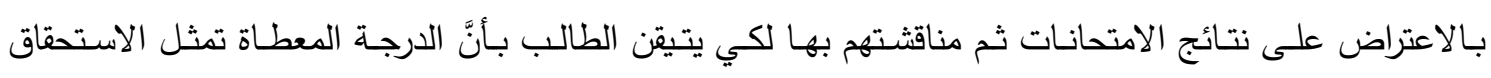

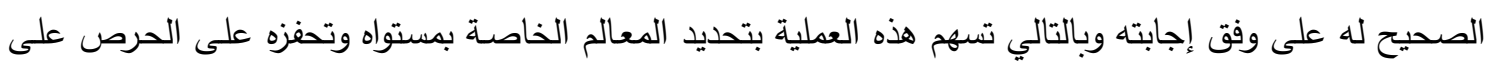

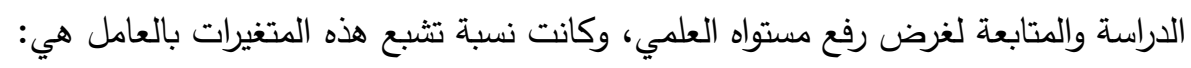
(50.0\%, 57.8\%, 63.8\%, 70.5\%, 76.0\%)

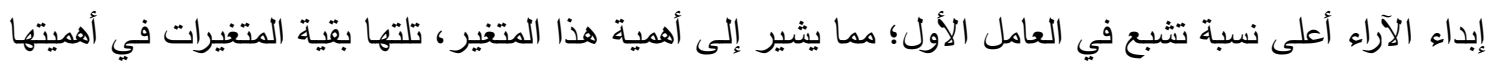

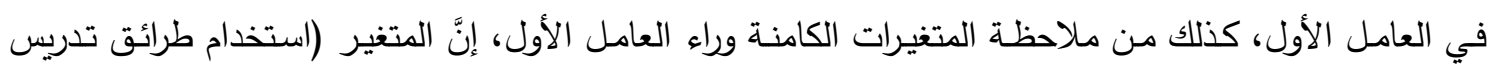

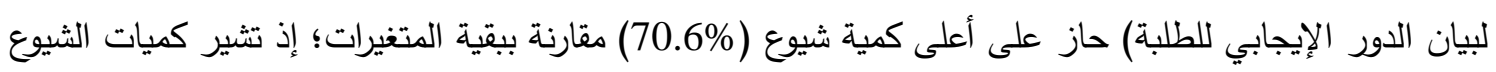

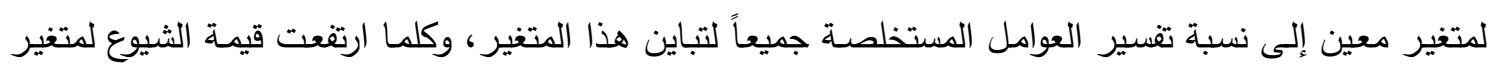
معين دل ذلك على أهمية هذا المتغير في ظاهرة الدراسة، وعلى العكس كلما انخفضت كمية الثيوع لمتغير معين

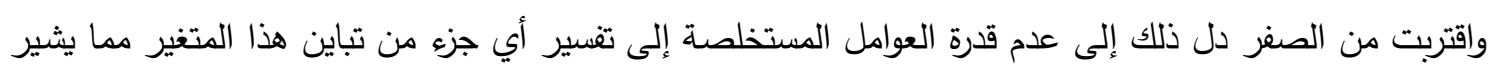

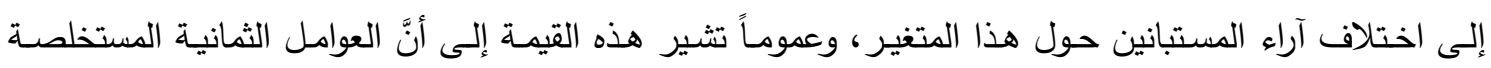

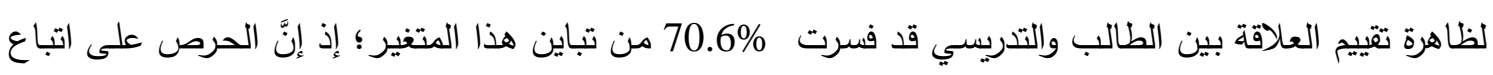

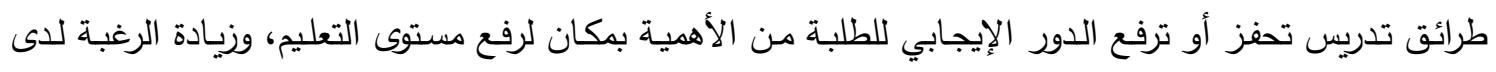

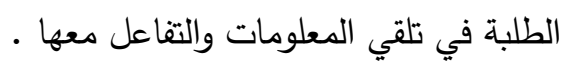

\section{العامل الثاني: لتشويق للمحاضرة باستخدام أساليب التقانات الاككترونية الحديثة}

يتمثل هذا العامل في اتباع أسـاليب التشويق للمحاضرة وذلك لغرض تحفيز الطلبة لثد انتباههم لمتابعـة المفردات العلمية الخاصـة بالمحاضرة، هذا فضلاً عن قيام التدريسي بتطوير مهاراته العلمية عن طريق استخدام

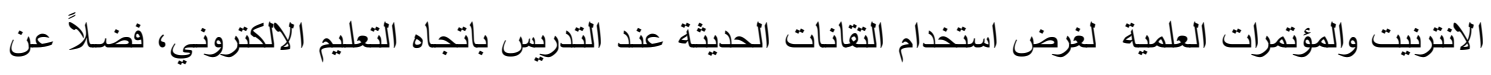

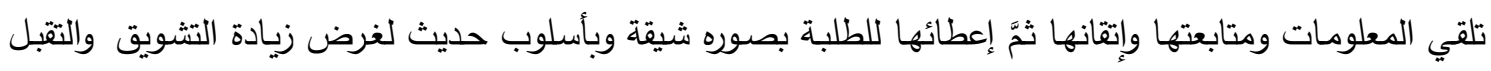

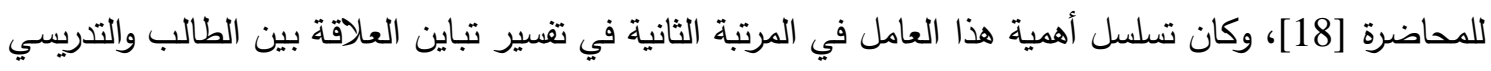
بمقدار (10.93\%) مقارنـة بالعوامل الأخرى مما يشير إلى أهميته، وقد انطوى تحت هذا فئ العامل ثـلاث متغيرات وهي: (استخدام أسلوب التشويق في المحاضرة، واستخدام التقانات الاككترونية الحديثة في التدريس باتجاهي التهاه التعليم الاككتروني، وقيام التدريسي بتطوير مهاراته التكنولوجية)، وكانت نسبة تثبع هذه المتغيرات بالعامل الثاني هي

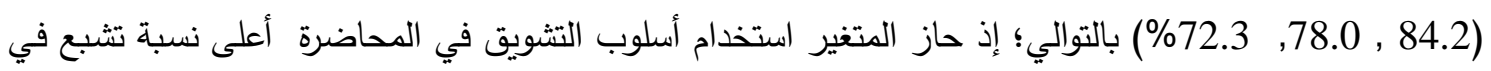

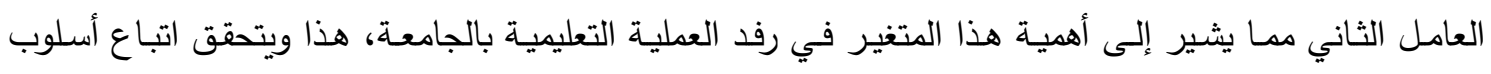

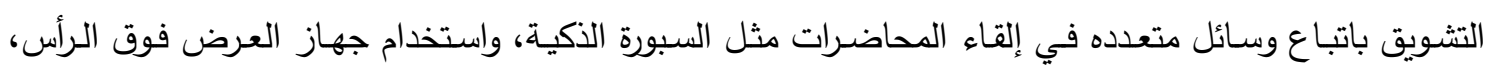

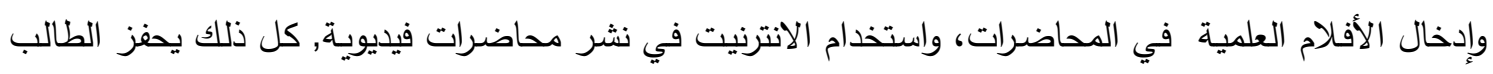

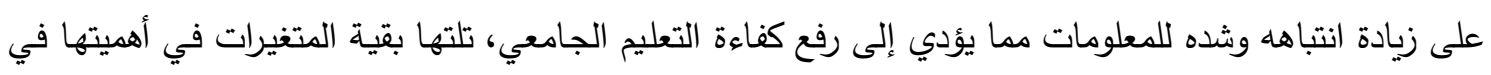

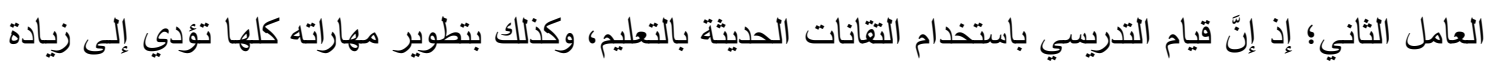


فاعلية التثويق للمحاضرة، وحتى يتمكن التدريسي من استخدام تكنولوجيا التعليم في العملية التعليمية فلا بد له من القدرات والمهارات والخبرات التي تمكنه بالتعامل مع تلك الأجهزة ووسائلها، وكذلك استخدامها في التدريس وإدارتها

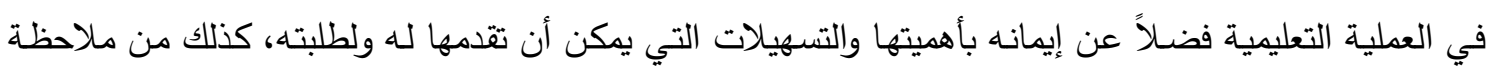

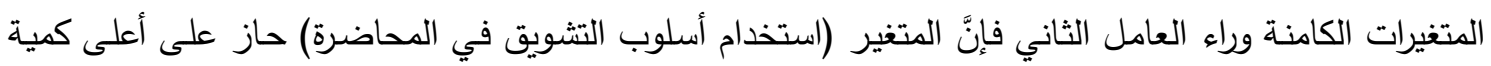

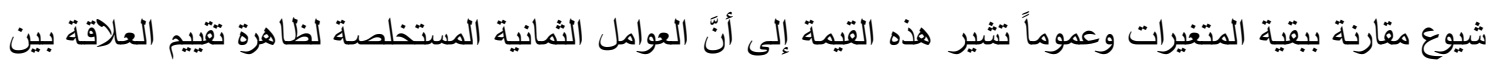
الطالب والتدريسي قد فسرت 75.7\% من تباين هذا المتغير •

\section{العامل الثالث: الالتزام بالدوام والحرص على الانتباه والتنافس العلمي.}

يتمثل هذا العامل بمبدأ الالتزام بالدوام والحرص على الانتباه فضلاً عن التنافس العلمي بين الطلبة بغية زيادة تلقي الطلبة على المعلومات وذلك بتثجيع التدريسي وقيامه بتوصيل المعلومات بأسلوب يؤدي إلى تحفيز الطلبة

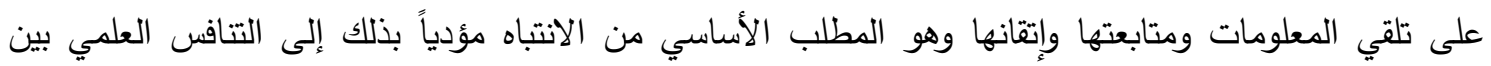

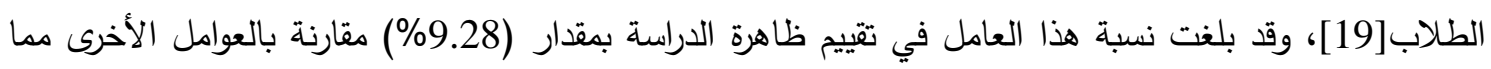
يشير إلى أهميته، وقد انطوى تحت هذا العامل ثلاثة متغيرات وهي:(الحرص على إلزام الطلبة بالدوام الرسمي،

والحرص على شدة انتباه الطلبة للدحاضرة وقطع حالة الثرود، والتثجيع على التتافس العلمي بين الطلبة).

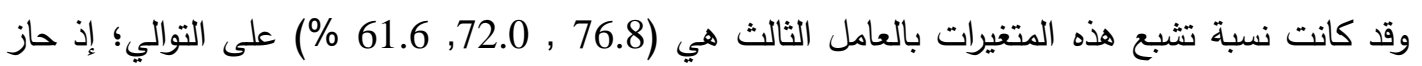
المتغير الحرص على التزام الطلبة بالدوام الرسمي أعلى نسبة تثبع في العامل الثاني مما يثير إلى أهمية هذا

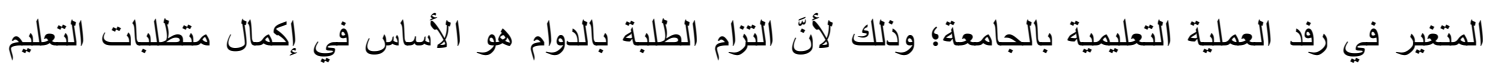
من انتباه ومتابعة المحاضرات، والتسابق والتنافس على تلقي المعلومات، كذلك من ملاحظة المتغيرات الكامنة وراء العامل الثالث فإنَّ المتغير (الحرص على إلزام الطلبة بالدوام الرسمي) حاز على أعلى كمية شيوع مقارنة ببقية

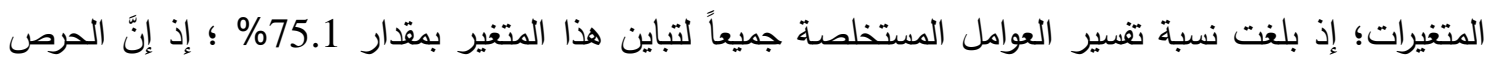
على التزام الطلبة بالدوام الرسمي هو أساس نجاح العملية التعليمية .

\section{العامل الرايع: استخدام التقارير والمقدمة التعريفية لكل محاضرة وتوضيح أهدافها}

يتمثل هذا العامل بمبدأ تكليف الطلبة بالتقارير العلمية ومناقشتها لغرض الحصول على تصور أوسع لفهر المواد التعليمية وإتقانها [20]، هذا فضلاً عن قيام التدريسي بإعطاء مقدمة تعريفية لعنوان المحاضرة وأهدافها وفائدتها، والأهداف التي تحققها بمناقثة الطلبة؛ إذ تساعد الطلبة على تلقي المعلومات ومتابعتها وإتقانها، وقد بلغت نسبة هذا العامل في تقييم طبيعة العلاقة بين الطرفين بمقدار (8.39\%) مقارنة بالعوامل الأخرى مما يثير إلى أهميته أيضاً، وقد انطوى تحت هذا العامل اثثين من المتغيرات هي: (تكليف الطلبة بالتقارير على وفق المجاميع، والتركيز على المقدمة التعريفية لكل محاضرة والأهداف التي تحققها) وكانت نسبة تشبع هذه المتغيرات بالعامل الرابع وهي (79.4, 58.2\%) على التوالي؛ إذ حاز المتغير التير تكليف الطلبة بالتقارير على وفق المجاميع أعلى نسبة تشبع في العامل الرابع مما يثير إلى أهمية هذا المتغير في رفات العملية التعليمية بالجامعة، كذلك من ملاحظة المتغيرات الكامنة وراء العامل الرابع فإنَّ المتغير (التركيز على لمئي

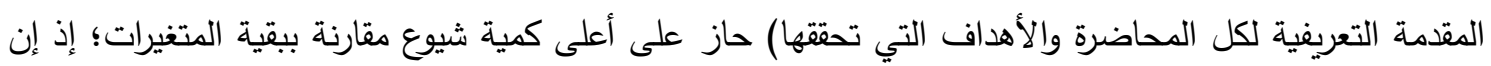
العوامل الثمانية المستخلصة لظاهرة تقييم الدراسة قد فسرت (72.2\%) من تباين هذا المتغير حلفي 
العامل الخامس: استخذام الأسئلة الثفوية لتقييم الطلبة أثناء المحاضرة.

يتمثل هذا العامل باستخدام الأسئلة الثفوية في بداية كل محاضرة لعدد معين من الطلبة، وقد تكون هذه الأسئلة خاصة بمعلومات المحاضرة السابقة أو حتى خاصة بالمحاضرة نفسها و بهذه العملية يقيم أولاً جميع الطلبة أثناء المدة الزمنية للكورس الدراسي وثانياً تحفز هذه العملية الطلبة على متابعة المحاضرات باستمرار وتهيئة أنفهه لهذه الاختبارات أثناء مناقشة الطلبة بهذه الأسئلة الشفوية وبتطوير مهاراتهم العلمية في المسيرة التعليمية [21]، وقد بلغت نسبة تأثير هذا العامل في تقييم العلاقة بين الطرفين بمقدار (6.97\%) مقارنة بالعوامل الأخرى، وقد انطوى

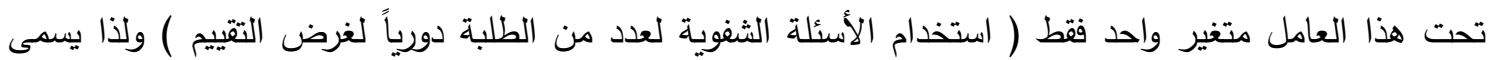
بالعامل الوحيد، وكانت نسبة تشبع هذا المتغير بالعامل الخامس هي (80.7\%) مما يثير إلى أهمية هذا المتغير

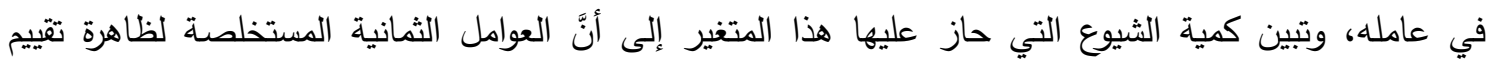
العلاقة بين الطلبة والأستاذ الجامعي قد فسرت (69.7\%) من تباين هذا المتغير •

\section{العامل السادس: مناقثة شكل الامتحانات مع الطلبة.}

يتمثل هذا العامل بقيام التدريسي بمناقشة الطلبة حول شكل وأسلوب الامتحانات التي سوف يختبرون بها

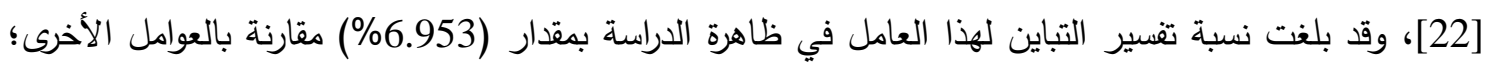
إذ يفيد استخدام الأستاذ الجامعي هذا المبدأ في إعطاء دور إيجابي للطلبة بإبداء آرائهم ومناقشة التدريسي لهم حول

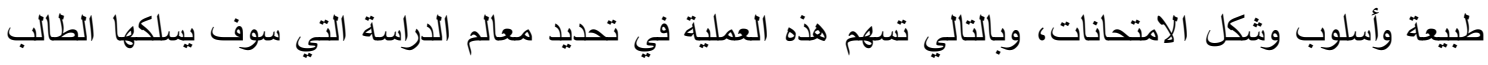

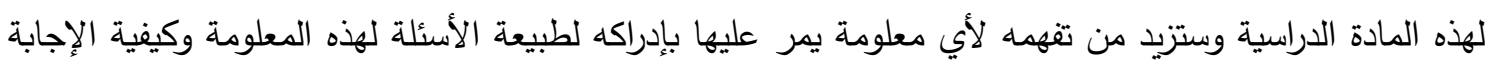
عليها، وسوف تؤدي هذه العملية إلى تحفيز مبدأ التنافس العلمي مع الطلبة الآخرين، وهذا هو المطلب الأساسي في التعليم الجامعي، وقد انطوى تحت هذا العامل متغيران هما (مناقثة التدريسي للطلبة حول شكل الامتحانات، واستخدام الأفلام العلمية معيناً في التدريس) وقد كانت نسبة تثبع هذين المتغيرين بعاملهما بمقدار (82.1, 42.2\%) على التوالي مما يثير إلى أهمية مناقثة الطلبة حول شكل الامتحانات في رفع كفاءة العملية التعليمية

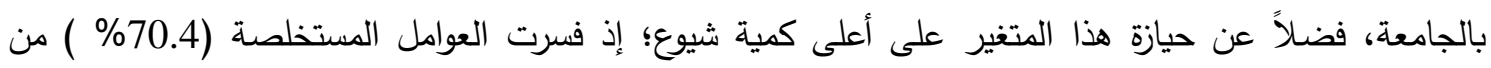

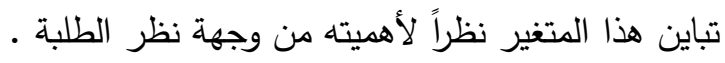
العامل السابع: تكليف الطلبة بالواجبات وإجراءات تفادي الفش.

يقوم التدريسي بتكليف الطلبة بواجبات لحل مسائل معينة ضمن المادة الدراسية والاستعانة بالانترنت مثلاً أو

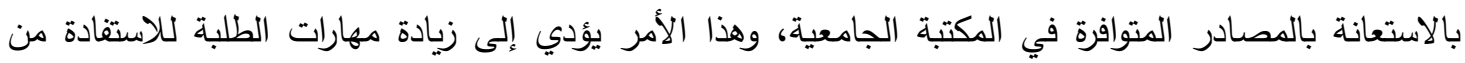

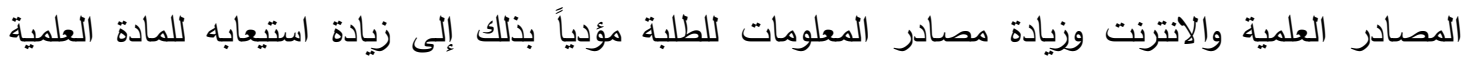

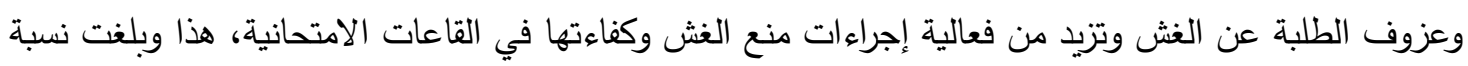

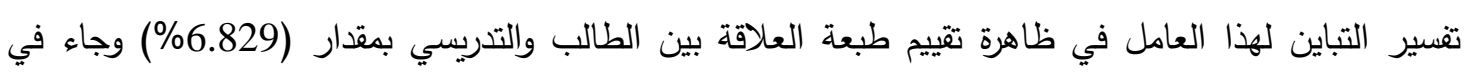
المرتبة السابعة في الأهمية مقارنة بالعوامل الأخرى، وقد انطوى تحت هذا العامل اثثان من المتغيرات وهي:

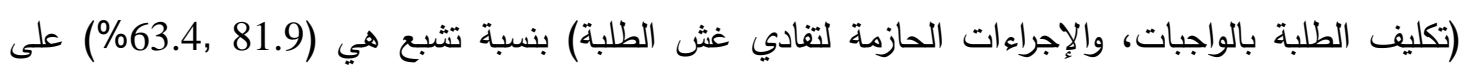
التوالي مما يشير إلى أهمية تكليف الطلبة بالواجبات الدراسية؛ إذ إنَّها تتيح للطلبة مراجعة للمادة التعليمية، هذاء

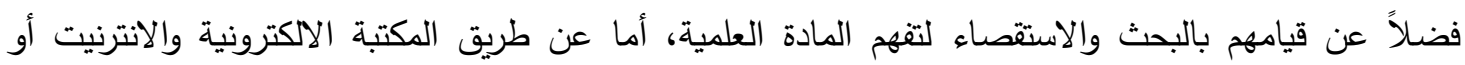


الكتب العلمية، وهذه العملية تؤدي إلى تطوير مهاراتهم في التعلم والاستيعاب للمواد التعليمية عن طريق استخدامهم للمصادر العلمية وتثير علاقة الارتباط الموجبة بين كلا المتغيرينن (r=0.25) إلى أنَّ مزيداً من تكليف الطلبة بالواجبات الدراسية وحلها تزيد من عزوف الطلبة عن الغش وتفعل من الإجراءات الحازمة لمنع الغش مؤدية بذلك إلى الارتقاء بالعملية التعليمية في الجامعة إلى مستويات أفضل، كذلك من ملاحظة المتغيرات

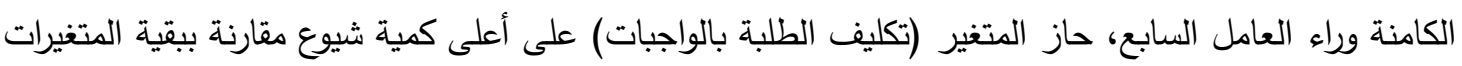

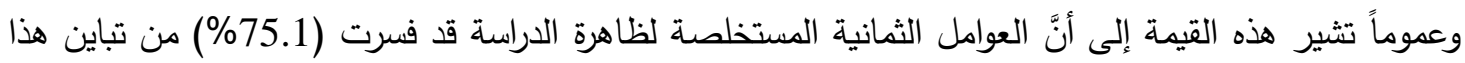
المتغير مما يشير إلى أهمية تكليف الطلبة بالواجبات الدراسية وحلها عن طريق متابعة المحاضرة أو الاستعانة بالدصادر العلمية والانترنت.

\section{العامل الثامن: التعامل الجيد مع الطلبة ومراعاة الفروق الفردية بينهم في المحاضرة.}

يشير هذا العامل إلى قيام التدريسي بالتعامل الجيد مع الطلبة ومراعاة الفروق الفردية بينهم أي: مراعاة الفرق

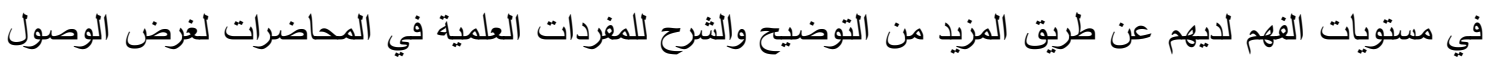

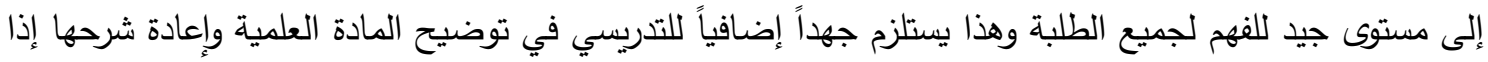
اقتضت الحاجة لذلك، وقد بلغت نسبة هذا العامل في تفسير تباين تقييم ظاهرة الدراسة بمقدار (6.81\%) مقارنة بالعوامل الأخرى، وقد انطوى تحت هذا العامل اثنان من المتغيرات وهي: (مراعاة الفروق الفردية بين الطلبة أثناء

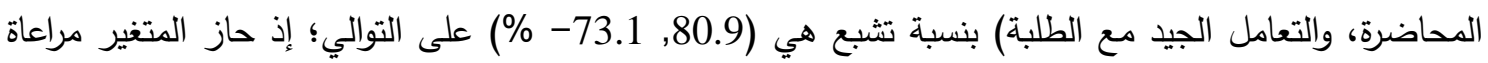

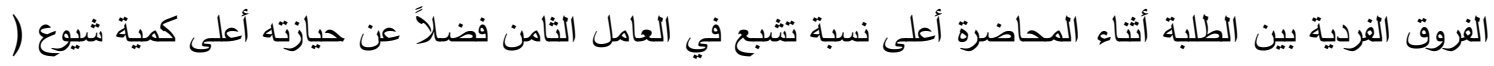

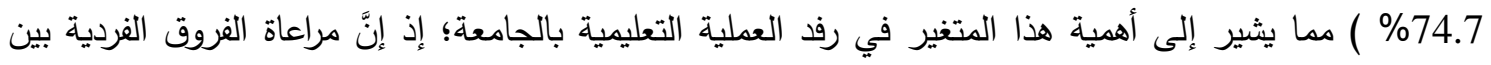
الطلبة أثثاء المحاضرة من الأهمية بمكان يستدعي من تدريسي الجامعة بذل المزيد من الجهود لرفع شريحة من الهن

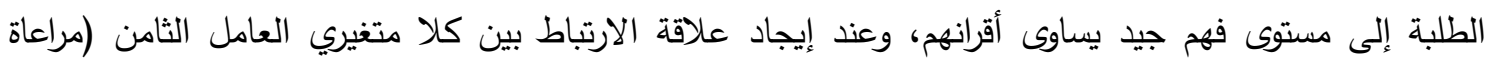

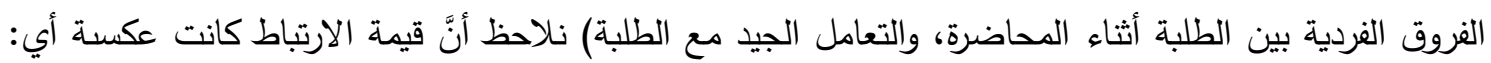

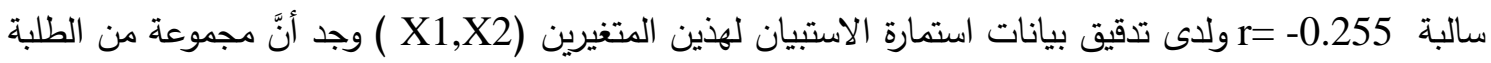

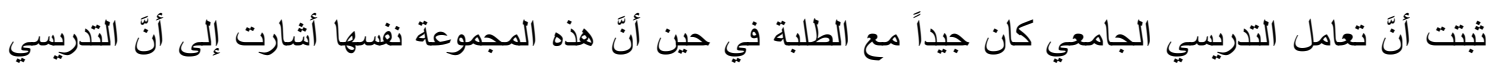

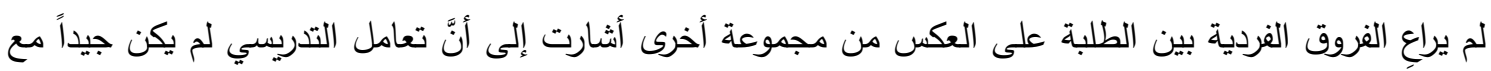

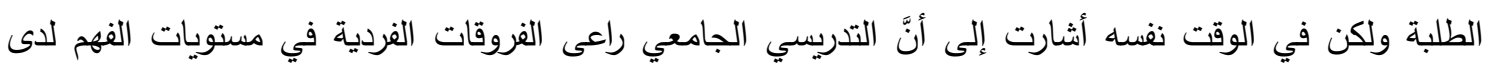

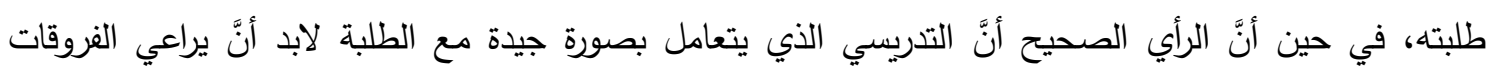

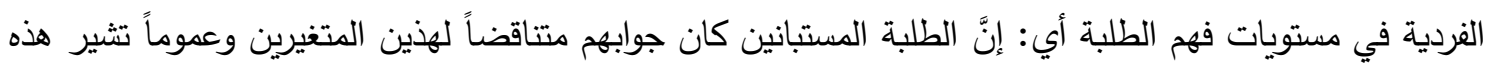
النتيجة إلى أنَّ التدريسي الجامعي يجب أن يحرص على تعامله الجيد مع طلبته، هذا فضلاً عن الحرص في

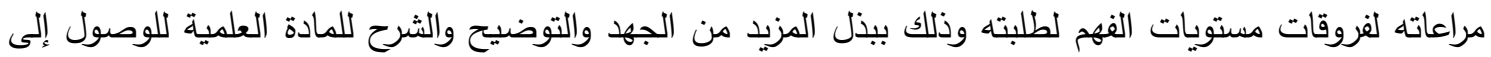

مستوى فهم جيد لجميع طلبته.

$$
\text { اختبار متغيرات الأنموذج }
$$

إنَّ تحليل المكونات الرئيسة (Principal component Analyses) يستخدم لتحديد العوامل الأولية في التحليل العاملي بوصفه أسلوباً غير متحيز في اختيار المتغيرات المستقلة وحصرها في مجاميع معنوية (عوامل) 
للظاهرة قيد الدراسة، وهو يستخدم أيضاً في تحليل الانحدار بوصفه وسيلة لإيجاد المتغيرات ذات العوامل الانحدارية

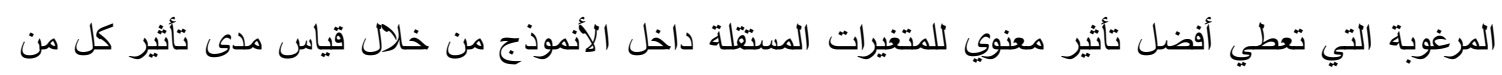
المتغيرات المستقلة داخل العامل في المتغير المعتمد فيه لغرض إيجاد العلاقات السببية بين المتغيرات واستبعاد

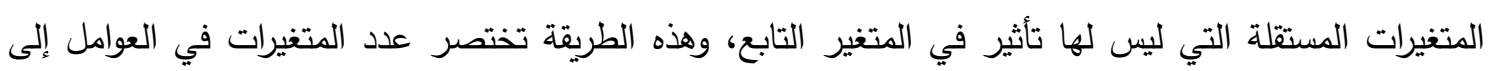

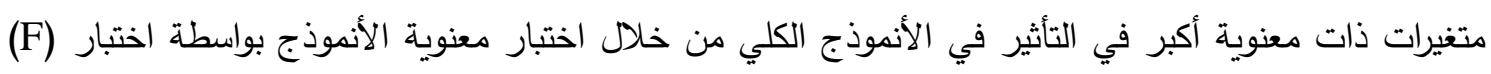

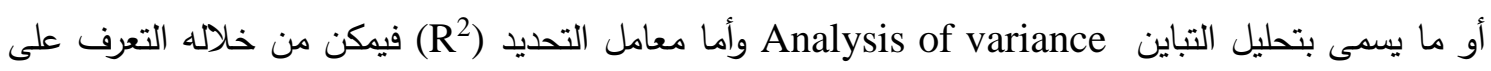
نسبة التأثير الإجمالي في المتغير المعتمد الذي يفسره المتغير أو المتغيرات المستقلة في الأنموذج ولعل أفضل فيل فئل الطرائق المستخدمة لهذه الحالة التي تحقق الشروط الإحصائية المطلوبة على الأنموذج القياسي طريقة معادلة الإني الانحدار الخطي المتعدد Multiple linear Regression Procedure والتي استخدامت بواسطة أنموذج الخوارزميات الجينية Genetic Algorithm Procedure لإيجاد قيم معامل المتغيرات الداخلة في أنموذج معادلة الانحدار فضلاً عن إيجاد ترتيب المتغيرات المستقلة على وفق أهميتها عن طريق حساب وزن المتغير المستقل (Beta)

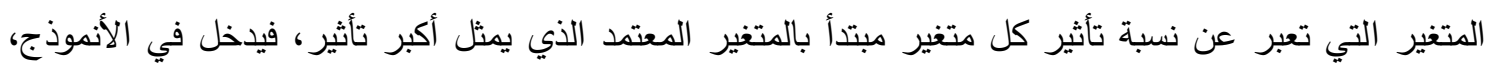

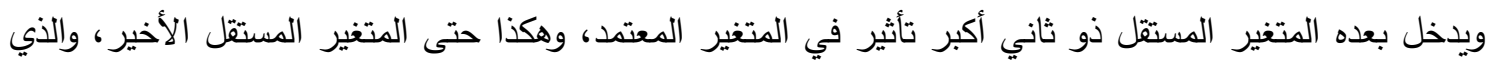

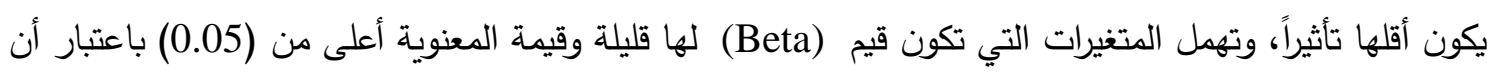

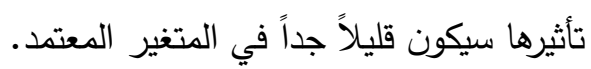

$f(x)=a_{0}+b X+e$

$f(X)=$ مصفوفة قيم المشاهدات

b= قيمة معلمات الانحدار

X= مصفوفة ثوابت من المتغيرات المستقلة

e= قيمة حدود الخطأ العشوائي

وفي جميع الحالات سيختار المتغير المعتمد في الأنموذج المختار للعامل بناءً على أعلى مقدار كمية شيوع

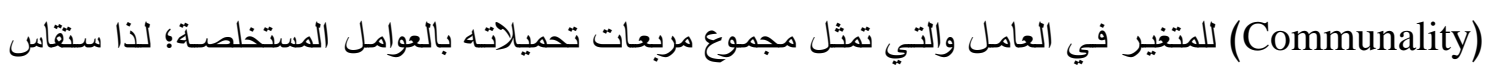

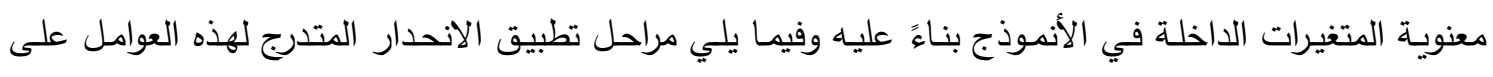
الظاهرة موضوع الدراسة.

العامل الاول: طرائق التدريس الهادفة لرفع المستوى التعليمي

عند تطبيق الخوارزميات الجينية لغرض اختبار قوة ووزن المتغيرات الداخلة في العامل الأول (X7,X8,X4,X3)

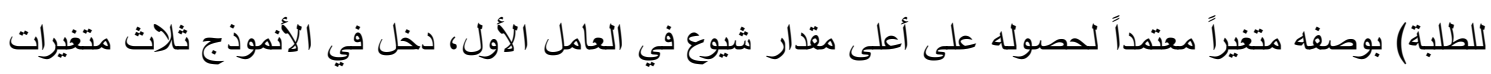

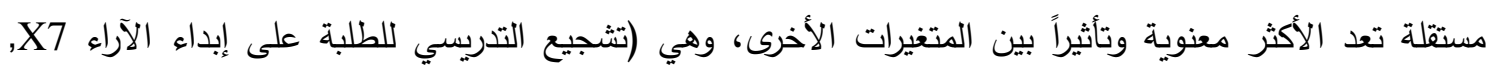

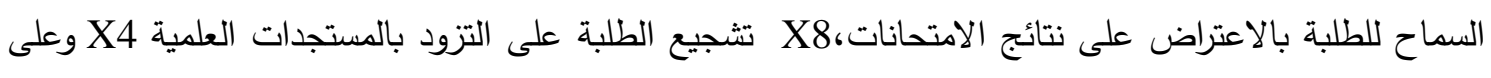

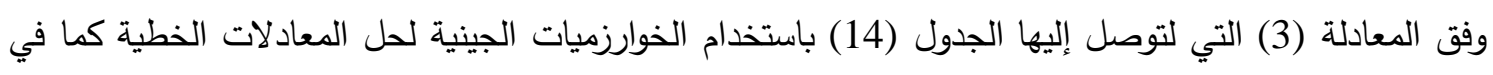
الأشكال (1,2) والمستتبطة من الدوال البرمجية: fal12 , fal13. 
$Y_{(\text {predicted })}^{X 10}=1.042+0.302 * X 7+0.231 * X 8+0.184 * X 4$

$\mathrm{R}^{2}=0.3 \quad$ Std_Err $=0.861$

function $\mathrm{z}=$ fal12( $(\mathrm{x})$

$a=x(1) ; b=x(2) ; c=x(3) ; d=x(4) ;$ load test_edu; $Q=0$; for $i=1: 115$

$\mathrm{Q}=\mathrm{Q}+\left(\mathbf{x 1 0}(\mathrm{i})-\mathrm{a}-\mathrm{b}^{*} \times \mathbf{7}(\mathrm{i})-\mathrm{c}^{*} \times 8(\mathrm{i})-\mathrm{d}^{*} \times 4(\mathrm{i})\right){ }^{\wedge} 2$;

end $Q=(Q / 114)^{\wedge} 0.5 ; z=Q$;

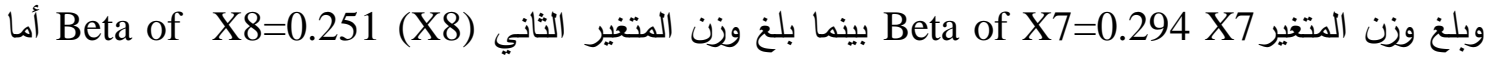

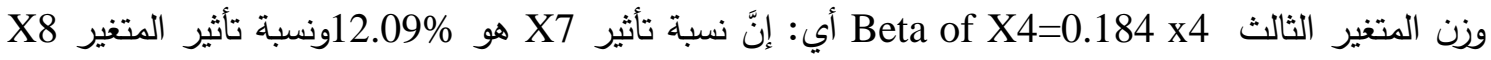

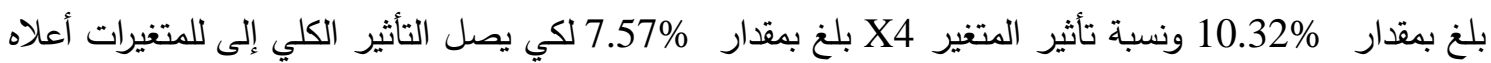
إلى 30\% في المتغير X10 باعتباره متغيراً معتمداً وبذلك يستبعد المتغير X3 (رفع مستوى التعليم بالعلاقة

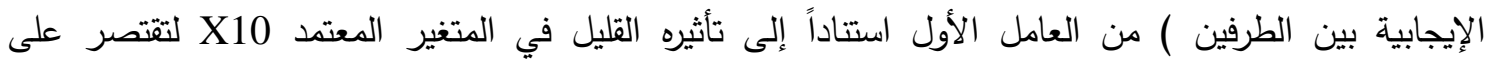
المتغيرات التالية ( X7,X8,X4 ) وهذه العملية تعدُّ ضمن مفهوم تتقيب البيانات، وكما موضح في الأشكال (1,2)

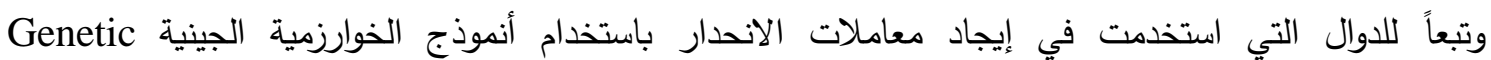

function $z=f a l 13(x) \quad b=x(1) ; c=x(2) ; d=x(3)$; load test_edu; $Q=0$;

\section{for $i=1: 115$}

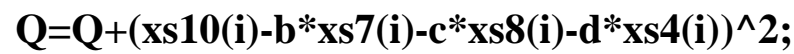
end $Q=(Q / 114) \wedge(0.5 ; z=Q$;

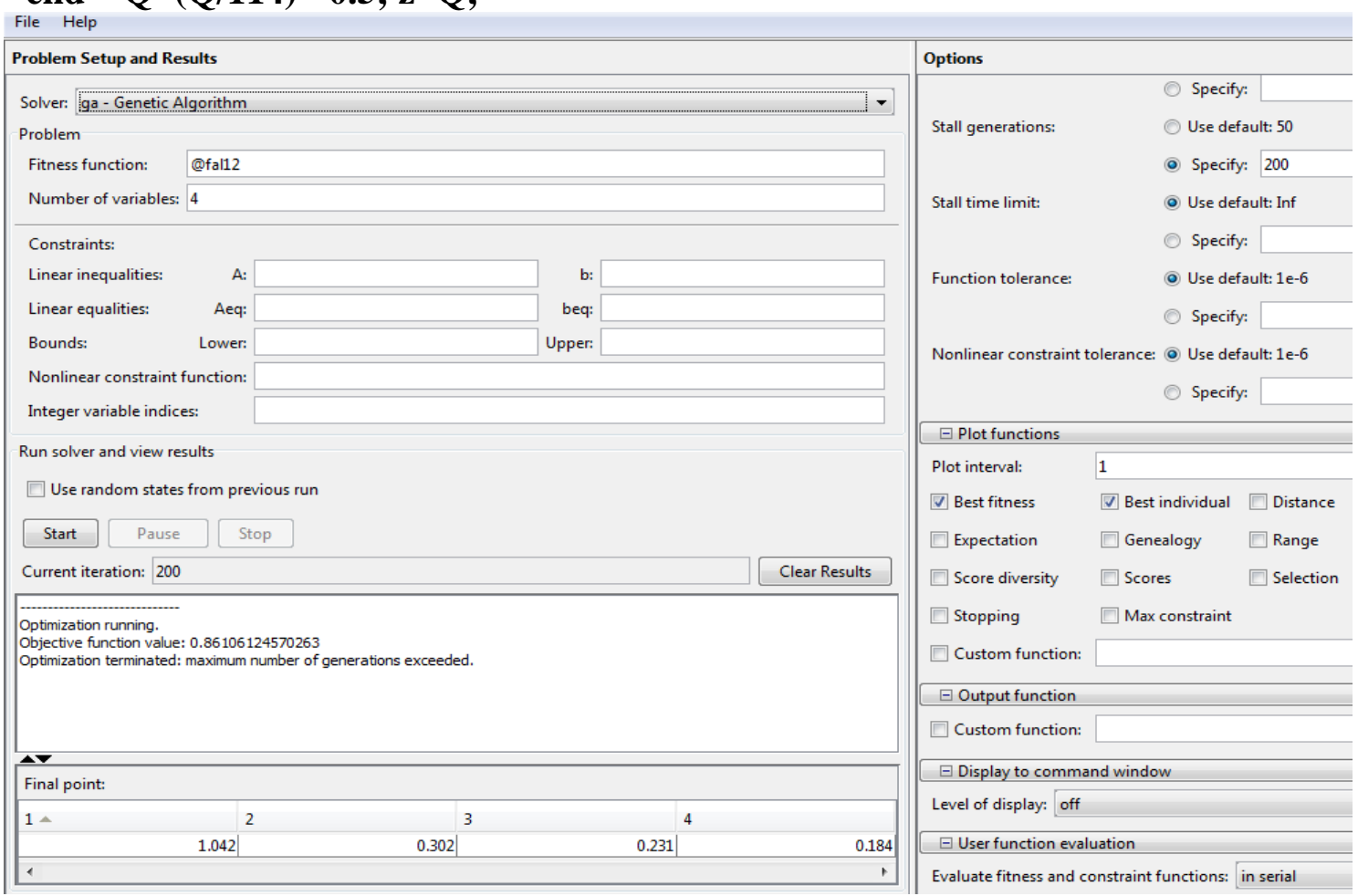

الثكل (1) استخدام الخوارزميات الجينية على متغيرات العامل الأول طرائق التدريس الهادفة لرفع المستوى التعليمي 


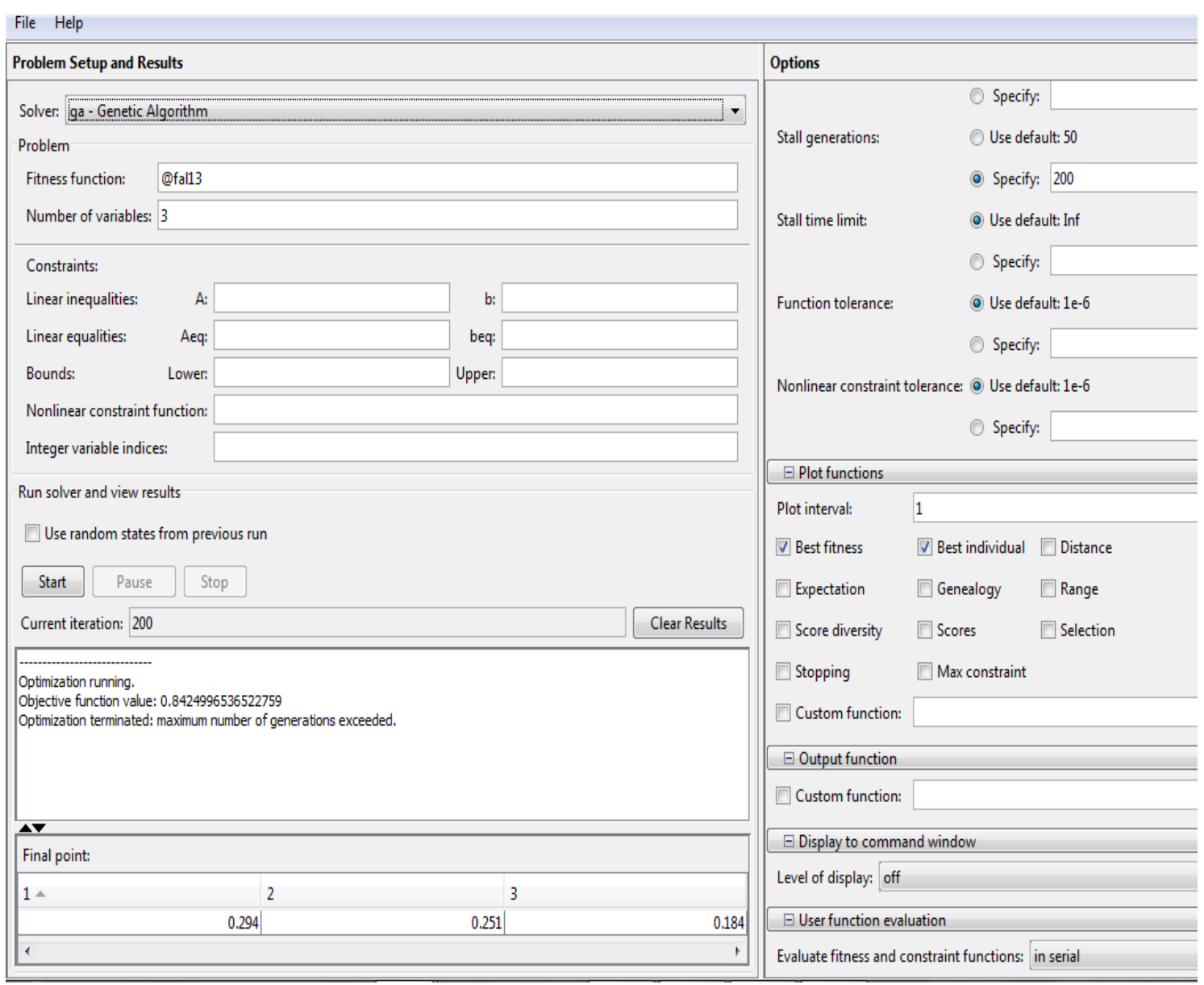

الثكل (2) استخدام الخوارزميات الجينية على متغيرات العامل الأول لغرض حساب قيم Beta لكل متغير

هذا وقد وصلت قيمة دالة الهدف لمعادلة الانحدار الخطي أعلاه (3) إلى (13) (13) الجدول رقم

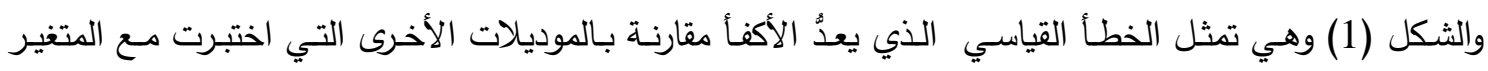

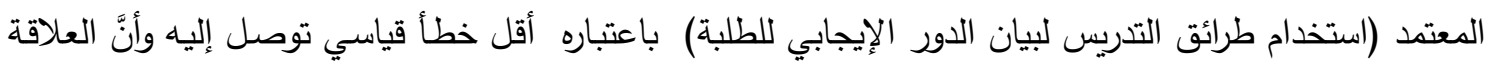
الطردية بين المتغيرات مـع المتغير المعتمد تؤكد أنَّ مزيداً من تثجيع التدريسي للطلبة على إبداء الآراء والسماح للطلبة بالاعتراض على نتائج الامتحانات وكذلك المزيد من تثجيع الطلبة على التزود بالمستجدات العلمية تؤدي

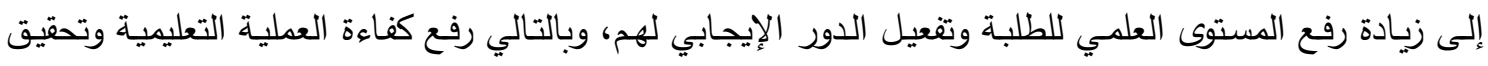
أهدافها، ومن الجدير بالذكر أنَّ تطبيق أنموذج الخوارزمية الجينة لكل عامل انضوى تحتئ تحته ثلاثة متغيرات أو أكثر

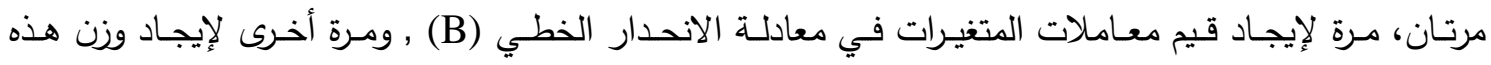
المتغيرات المستقلة وتأثيرها في المتغير المعتمد (Beta) وذلك بعد طرح قيم مصفوفة المتغير من معدله وتقسيمها

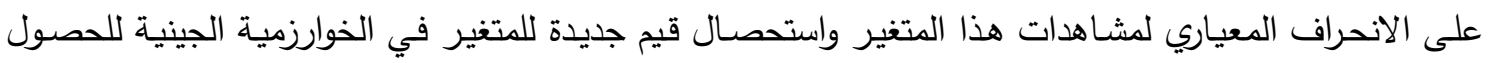
على أوزان هذه المتغيرات في أنموذج معادلة الانحدار، وخرج من متغيرات العامل الأول متغير واحد فقط (X3)

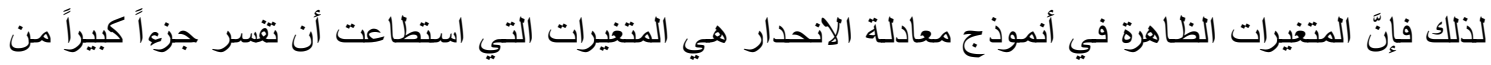

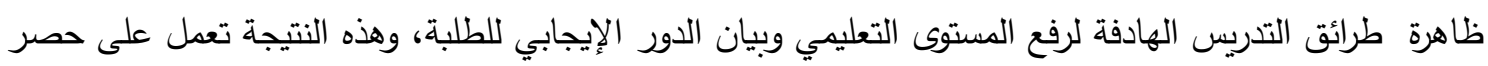

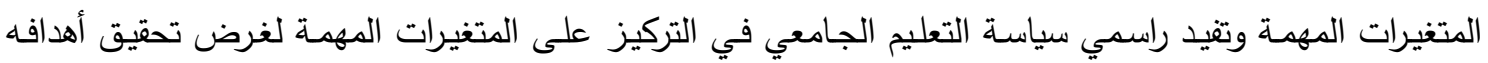

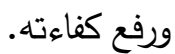


الجدول رقم (13) أنموذج الموديل الذي توصل إليه في تحليل الانحدار لمتغيرات العامل الأول

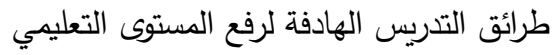

\begin{tabular}{|c|c|c|c|c|c|c|c|c|c|}
\hline النموذج & معامل & التحديد & معامل التحديد & قيمة الخطأ & معامل التحديد & F المتغيرة & درجة الحرية & درجة الحرية & مستوى \\
\hline 1 & .547 & .300 & .271 & .861 & .028 & 4.336 & 1 & 111 & .040 \\
\hline
\end{tabular}

الجدول رقم (14) معاملات متغيرات معادلة الانحدار لأنموذج الموديل التي توصل إليها لمتغيرات العامل الأول طرائق التتريس الهادفة لرفع المستوى التعليمي

\begin{tabular}{|c|c|c|c|c|c|c|c|c|}
\hline & \multicolumn{2}{|c|}{ المعامل النموذج } & \multirow{2}{*}{$\begin{array}{c}\text { القياسي } \\
\text { الخطأ } \\
\text { القيأ }\end{array}$} & \multirow[t]{2}{*}{ 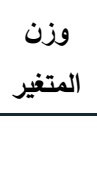 } & \multirow{2}{*}{\begin{tabular}{|c|}
$\begin{array}{c}\text { ق } \\
\mathbf{T}\end{array}$ \\
2.581
\end{tabular}} & \multirow{2}{*}{ المغنوية } & \multirow{2}{*}{ حلصود القيمة } & \multirow{2}{*}{ حدود القيمة } \\
\hline & (لثابت) & 1.042 & & & & & & \\
\hline & تثجيع التدريسي للطلبة على ابداء الآراء (X7) & .302 & .082 & .294 & 3.506 & .001 & .125 & .451 \\
\hline & $\begin{array}{r}\text { السماح للطلبة بالاعتراض نتائج الامتحانات } \\
\text { (X8) }\end{array}$ & .231 & .082 & .251 & 2.819 & .006 & .069 & .395 \\
\hline & تثجيع الطلبة على التزود بالمستجدات العلمية & .184 & .088 & .184 & 2.082 & .040 & .009 & .360 \\
\hline
\end{tabular}

المتغير المعتد: استخذام طرائق تدريس لبيان الدور الإيجابي للطلبة.

العامل الثاني: التشويق للمحاضرة باستخدام أساليب التقانات الاكترونية الحديثة.

عند تطبيق تحليل الانحدار الخطي المتعدد Multiple Linear Regression باستخدام طريقة الخوارزمية الجينية لغرض اختبار قوة المتغيرات (x16, x9) الداخلة في العامل الثاني بوصفها متغيرات مستقلة مع متغير X12 العامل الثاني، بقي كل من المتغيرين X16, X9 في أنموذج معادلة الانحدار لتأثيرهما العالي والمعنوي في معيتهي المتغير المتمد X12 وعلى وفق المعادلة التالية التي توصل إليها الجدول (16). $Y_{(\text {predicted })}^{X 12}=0.835+0.425 * X 16+0.38 * X 9$

$\mathrm{R}^{2}=0.40$

Std_Err=0.67

وبلغ وزن تأثير المتغير Beta of X16=0.4 أي: إنَّ نسبة تأثير X16 هو بمقدار 21.3\% في حين بلغ وزن المتغير Beta X9=0.35 أي: إنَّ نسبة تأثير المتغير X9 هو بمقدار 18.7\% ليكون الأثثر الكلي لكلا المتغيرين بمقدار 40\% في المتغير المعتمد X12, وبذلك تبقى المتغيرات الثلاثة (X12,X16,X9) هي المؤثرة في العامل الثاني بدرجة عالية وعلى مستوى معنوية sig=0.001، هذا وقد وصلت قيمة دالة الهدف لمعادلة الانحدار الخطي أعلاه إلى (0.67) الجدول رقم (15) وهي تمثل الخطأ القياسي الذي توصل إليه باستخدام أنموذج الخوارزميات

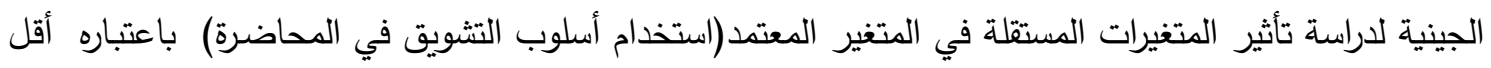
خطأ قياسي تُوصل إليه وأن العلاقة الطردية بين X16,X9 مع المتغير المعتمد X12 تؤكد أنَّ استخدام التدريسي باتئي

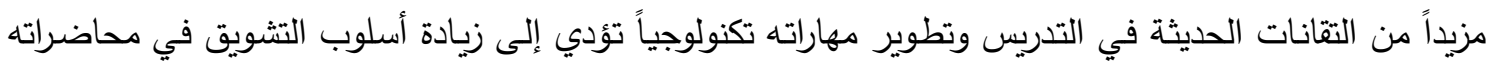


وبالتالي رفع كفاءة العملية التعليمية وتحقيق أهدافها، وهذه النتيجة تعمل على حصر المتغيرات المهمة وتفيد راسمي سياسة التعليم الجامعي في التركيز على المتغيرات المهمة لغرض تحقيق الهيق أهدافه. الجدول رقم (15) الأنموذج الذي تُوصل إليه في تحليل الانحدار لمتغيرات العامل الثاتئي الثاني

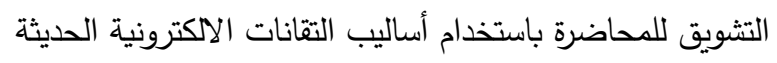

ملخص النموذج

\begin{tabular}{|c|c|c|c|c|}
\hline النموذج & معامل الارتباط & معامل التحديد & معامل التحديد المعدل & للتخأ القياسين \\
\hline$\overline{1}$ & $.625^{\mathrm{a}}$ & .40 & .380 & .67 \\
\hline
\end{tabular}

الجدول رقم (16) أنموذج معاملات متغيرات معادلة الانحدار الذي تُوصل إليها لمتغيرات العامل الثاني

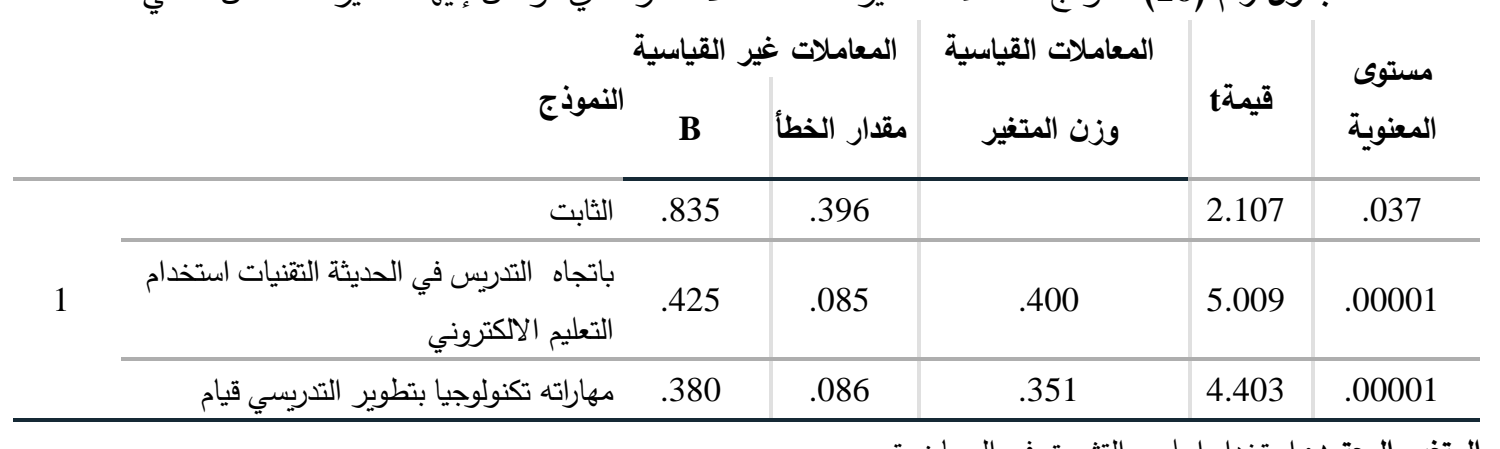

المتغير المعتمد: استخدام اسلوب التثويق في المحاضرة

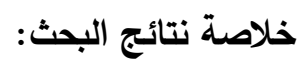

طبقت الخوارزميات الجينية لغرض اختبار قوة المتغيرات الداخلة ووزنها في كل عامل التي وصفت بأنها

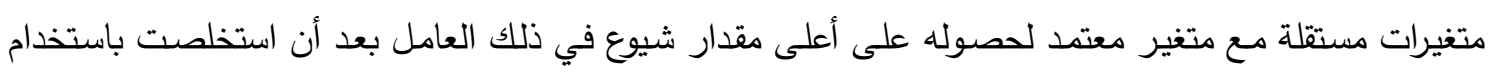

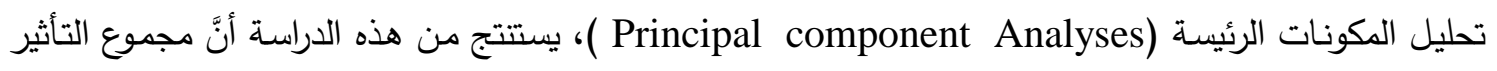

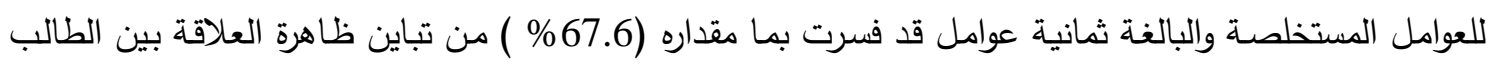
الجامعي والتدريسي، وكان لكلا العاملين ( طرائق التدريس الهادفة لرفع المستوى التعليمي وتحفيز الدور الإيجابي

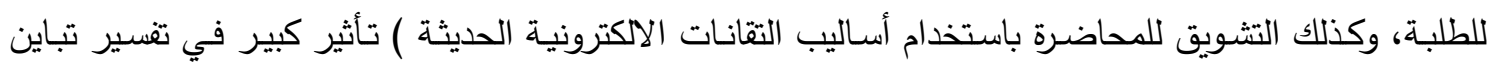
طبيعة العلاقة بين الطالب والأستاذ؛ فقد احتل هذان العاملان المرتبة الأولى والثانية في تقسير التباين وبنسبة 22.5 مما يشير إلى الأثر العالي لتحفيز الدور الإيجابي للطلبة وكذلك استخدام أسلوب التشويق في العملية

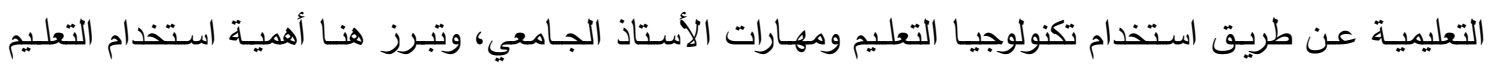
الاككتروني وخصوصاً في جائحة كورنا لرفد العملية التعليمية ورفع كفاءتها وجعلها متواصلة وبدون توقف للارتقاء بأبعاد وجودة التعليم العالي، هذا وقد أشارت العوامل الثلاثة اللاحقة وهي ( الحرص على على الدوام والمتابعة والتتافس كلى العلمي تعليم بأهمية المحاضرة وأهدافها والمطالبة بالتقارير ، واستخدام الأسئلة الثفوية في عملية تقييم الطلبة) لترفع كفاءة العلاقة بين الطالب الجامعي والأستاذ إلى نسبة 47.0\% فهية وفذه النتائج تعطينا الطريق الصحيح حول كيفية دراسـة المشكلات ومعالجتها التي تم ذكرت في مقدمـة البحث، وبنفس الوقت كيفية استخدام التحليل العـاملي والخوارزميات الجينية في دراسة تثييم العملية التعليمية في الجامعة والمؤسسات التربوية. 
استكمالاً لمنهجية الدراسة وتواصلاً مع استتاجاتها نشير إلى عدد من التوصيات التي نرى ضرورة أخذها

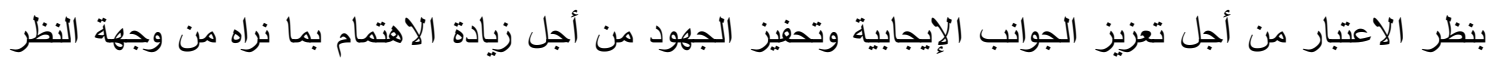
البحثية ملائمة للمساهمة في تطوير التعليم الجامعي ومنها: أنه يفضل تطبيق هذا البحث على مؤسسات تعليمية أخرى لتتاول كافة الجوانب التي تغطي أهمية التعليم الجامعي كتطور حديث في نجاح المسيرة العلمية في الجامعات

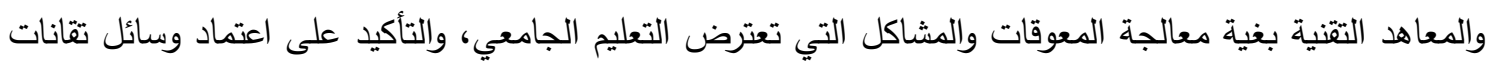

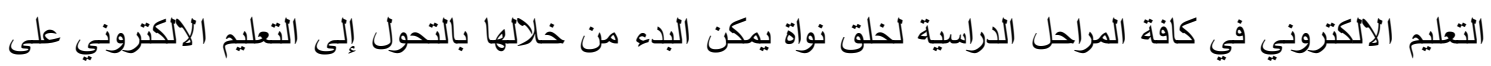
مستوى المؤسسات التربوية ومؤسسات التعليم العالي. 


\section{المصادر}

عادل, أحمد هدو (2014). التحليل العاملي وتطبيقه على العملية التعليمية في إحدى الجامعات الأردنية الخاصة. مجلة كلية بغداد للعلوم الاقتصادية الجامعة.

سالم, محمد البياتي، وحسن ناصر إبراهيم (2007). أثر العوامل الاقتصادية والاجتماعية على تسرب طلبة الجامعات. مجلة كلية بغداد للعلوم الاقتصادية الجامعة.

الحميد، داود ماهر محمد (1996). بناء برنامج تدريبي لأعضاء هيئة التدريس الجامعية في ضوء أدائهم الصفي. أطروحة دكتوراه، الجامعة المستتصرية، العراق.

الزاملي، علي عبد جاسم، وعباس سهيلة محمد (1989) بناء مقياس لتقويم التدريس في جامعة صلاح

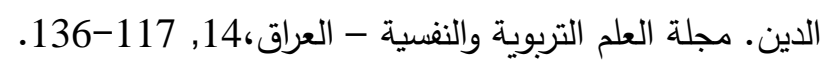

أبو فأرة، يوسف (2006)، إشراك الطلبة في تقييم جودة التعليم العالي. أوراق عمل المؤتمر العربي الأول

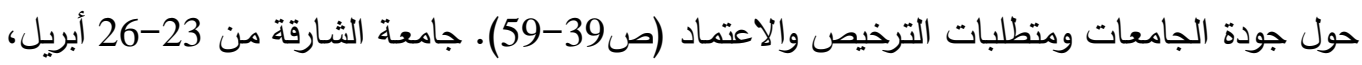
القاهرة: المنظمة العربية للتمية الادارية. إبراهيم، رضا رزق، والطيب، يوسف حسن (2000), علاقة بعض المتغيرات في تقييم الأستاذ الجامعي

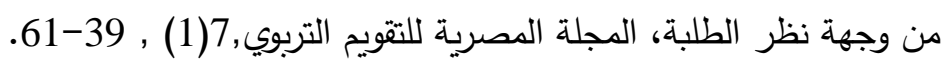
الثايب، عبد الحافظ (2007) مدى اختلاف تقديرات الطلبة لفاعلية التدريس الجامعي باختلاف مستوى المادة الدراسية ومجالها ونوعها. مجلة كلية التربية - جامعة الإمارات العربية المتحدة,24-99. الازيرجاوي، فاضل محسن (2010). تطوير أداة لقياس فاعلية التدريس في الجامعات العراقية من وجهة نظر الطلبة. مجلة القادسية للعلوم الإنسانية. المجلد الثالث عشر، العدد 2 / 2010, 183-210. عقراوي، متـي (1971). الإعـداد المهني للمـدرس الجـامعي. بحـث مقدم الـى المؤتمر الأول للتعليم الجامعي، جامعة بغداد، العراق.

أبو فايد، أحمد, (2016). التحليل العاملي: مفهومه، أهدافه، شروطه، أنواعه، خطواته، مثال تطبيقي

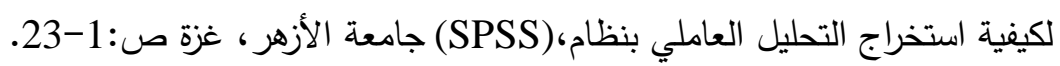
الكبيسي كامل ثامر ; وعبد الرحمن، أنور حسين; وخلف، طاهرة عيسى (1989). معايير تقويم عضو

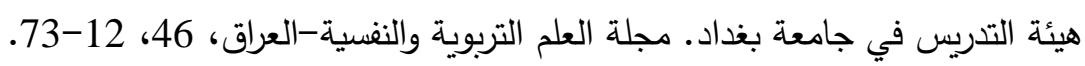

منسي، محمود عبد الحليم (2000). تقويم أداء عضو هيئة التدريس من وجهة نظر الطلاب كمدخل

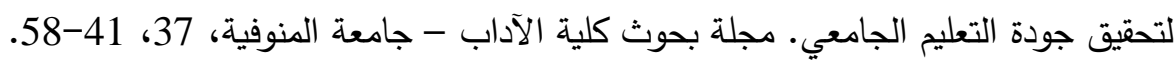

[13] Carle, A.C. (2009). Evaluating college students' evaluations of a professor's teaching effectiveness across time and instruction mode (online vs. face-to-face) using a multilevel growth modeling approach. Computers and Education, 53 (2), 429-435. 
[14] Markus Z"oller,2012. A Comparison between Principal Component Analysis and Factor Analysis UNIVERSITY OF APPLIED SCIENCES W“URZBURGSCHWEINFURT, 16.07. pp:1-4.

[15] Isabel Izquierdo, Julio Olea and Francisco José Abad 2014. Exploratory factor analysis in validation studies: Uses and recommendations. Psicothema 2014, Vol. 26, No. 3, 395-400.

[16] Christian Acal, Ana M. Aguilera, and Manuel Esca,2020. New Modeling Approaches Based on Varimax Rotation of Functional Principal Components, Mathematics 2020, 8, 2085; doi:10.3390/math8112085

[17] Owens, T.L. 2017. Higher education in the sustainable development goals framework. Eur. J. Educ., 52,414-420.

[18] Freeman, S., S. L. Eddy, M. McDonough, M. K. Smith, N. Okoroafor, H. Jordt, and M. P. Wenderoth. 2014. Active learning increases student performance in science, engineering and mathematics.Proc.Natl.Acad.Sci.USA 111:8410-8415. (23) (PDF) Improved student achievement through gamification and the flipped classroom.

[19] Wiliam, D. and Bartholomew, H. (2004) "It's not which school but which set you're in that matters: the influence on ability-grouping practices on student progress in mathematics." British.

[20] University of Reading,2019. Report Writing. Study Advice Study Guides, pp: 17. https://libguides.reading.ac.uk/reports.

[21] Gordon Joughin ,2010. A Short Guide to Oral Assessment, Deakin University pp:1-21. https://www.researchgate.net/publication/228844594.

[22] Eberly Center Eberly: (412) 268-2896 Carnegie Mellon University 5000 Forbes Ave Pittsburgh, PA 15213Teaching Excellence \& Educational Innovation, https://www.cmu.edu/ 
المتارة الاستبيان

دراسة طبيعة العلاقة بين الطالب الجامعي والأستاذ بغية رفد العملية التعليمية الإنية

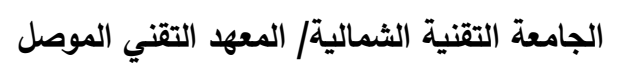

عزيزي الطالب يرجى تفضلكم بالإجابة على جميع الأسئلة التالية بإحدى الاختيارات المبينة في الجدول التالي (1,2,3,4,5)، وعلى وفق ما تتفق معه أو تراه مناسباً؛ وذلك للتوصل إلى طبيعة العلاقة بين الطالب الجامعي والأستاذ

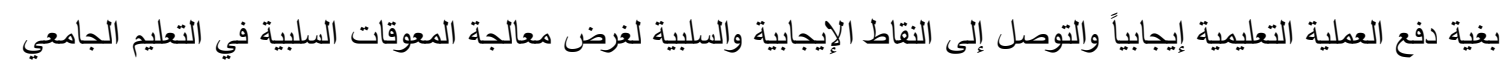

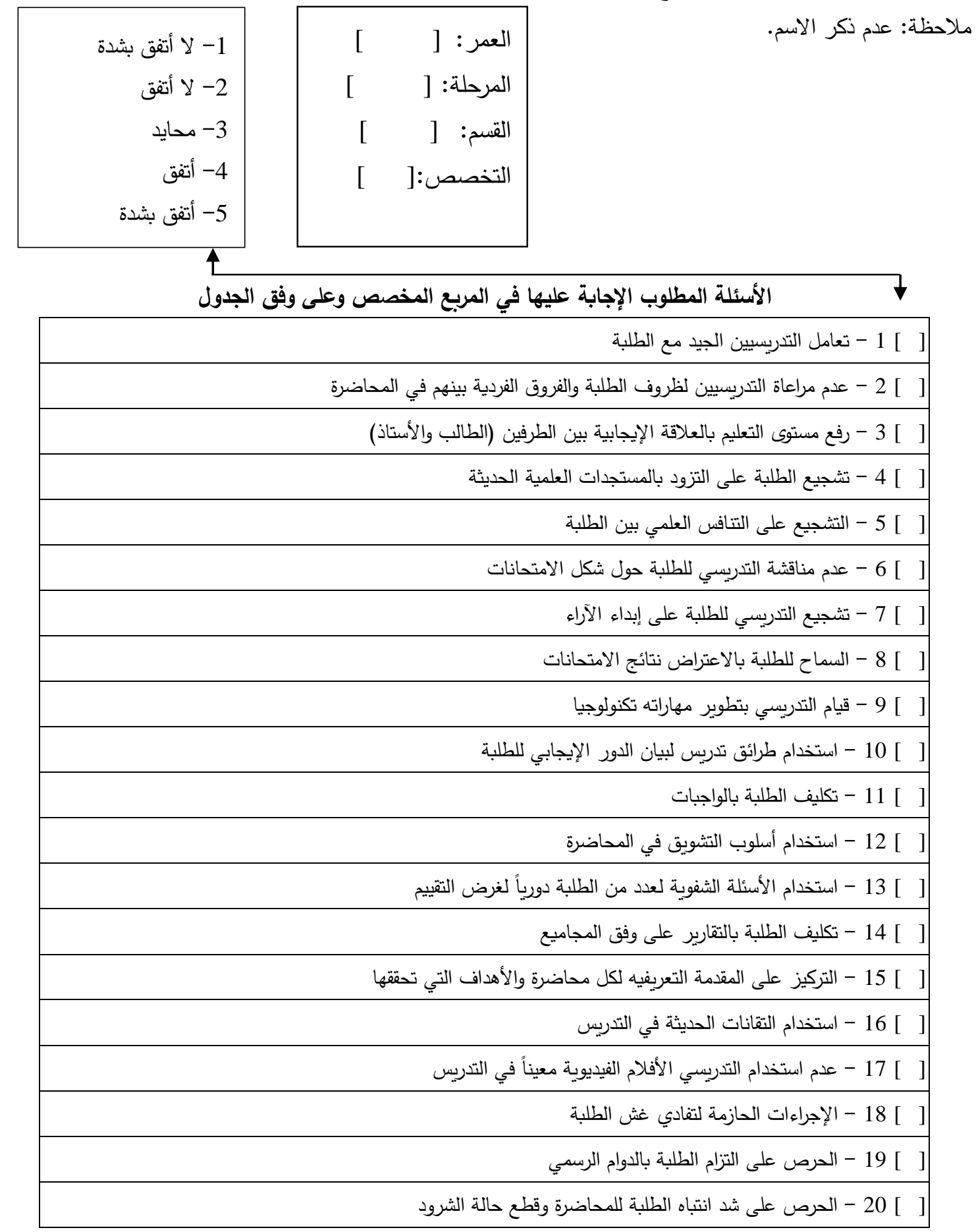


وفيما يلي بيانات الاستبيان الخاصة بطلبة المعهد التقني الموصل علماً أنه قد تمت مراعاة الأسئلة السلبية أو التي بها

نفي حيث أزيل النفي وعكس الإجابات الخاصة بها وهي الأسئلة رقم ( 2,6,17 )

ملحق الجدول (17) بيانات الاستبيان لطلبة المعهد التقني الموصل - الجامعة التقنية الثمالية

\begin{tabular}{|c|c|c|c|c|c|c|c|c|c|c|c|c|c|c|c|c|c|c|c|c|c|c|}
\hline No & $x 1$ & $\mathrm{x} 2$ & $x 3$ & $x 4$ & \begin{tabular}{l|}
$x 5$ \\
\end{tabular} & $\times 6$ & $x 7$ & $\mathrm{x} 8$ & $\begin{array}{ll}\mathrm{x} 9 \\
\end{array}$ & \begin{tabular}{l|l}
$\mathrm{x} 10$ \\
\end{tabular} & $\mathrm{x} 11$ & $\mathrm{x} 12$ & $\mathrm{x} 13$ & \begin{tabular}{|l|}
$x 14$ \\
\end{tabular} & $\mathrm{x} 15$ & \begin{tabular}{l|l|}
$\mathrm{x} 16$ \\
\end{tabular} & \begin{tabular}{|l|}
$x 17$ \\
\end{tabular} & \begin{tabular}{l|}
$x 18$ \\
\end{tabular} & \begin{tabular}{|l|}
$x 19$ \\
\end{tabular} & $\mathrm{x} 20$ & الفس العلمي & التخصص \\
\hline 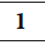 & 5 & 4 & 4 & 5 & 5 & 4 & 3 & 3 & 5 & 5 & 3 & 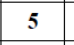 & 2 & 5 & 5 & 5 & 3 & \begin{tabular}{l|l|}
3 \\
\end{tabular} & 3 & 5 & أنظطة حاسوب & \\
\hline 2 & 5 & 3 & 4 & 3 & 1 & 1 & 5 & 1 & 1 & 1 & 1 & 4 & 3 & 1 & 3 & 1 & 2 & 5 & 1 & 3 & أنظمة حاسوب | & اداري ل ادي \\
\hline 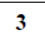 & 1 & 5 & 1 & 1 & 5 & 5 & 1 & 1 & 1 & 1 & 1 & 5 & 1 & 1 & 1 & 1 & 2 & 5 & 4 & 5 & |أنظمة حاسوب | & 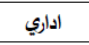 \\
\hline 4 & 3 & 2 & 4 & 4 & 4 & 5 & 4 & 2 & 3 & 1 & 3 & 4 & 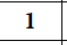 & 2 & 4 & 2 & 3 & 4 & 4 & 5 & أنظطة حاسوب & اداري ادري \\
\hline 5 & 4 & 2 & 2 & 3 & 4 & 5 & 2 & 4 & 1 & 2 & 4 & 4 & 5 & 2 & 3 & 4 & 5 & 1 & 3 & 4 & |أنظمة حاسوب | & الداري ل إي \\
\hline 6 & 2 & 3 & 4 & 1 & 3 & 5 & 1 & 1 & 1 & 2 & 3 & 4 & 3 & 3 & 1 & & & & & & أنظمة حاسوب & الداري ل إي \\
\hline 7 & 3 & 5 & 2 & 1 & 3 & 1 & 1 & 3 & 4 & 2 & 1 & 5 & 5 & 5 & 5 & 5 & 1 & 5 & 5 & 5 & أنظمة حاسوب | & اداري \\
\hline 8 & 4 & 5 & 5 & 5 & 5 & 5 & 4 & 5 & 5 & 4 & 4 & 4 & 4 & 4 & 4 & 4 & 5 & 5 & 4 & 5 & |أنظطة حاسوب | & الداري إي إي \\
\hline 9 & 4 & 5 & 2 & 3 & 4 & 1 & 3 & 5 & 2 & 1 & 3 & 4 & 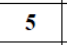 & 2 & 3 & 1 & 5 & 1 & 5 & 5 & أنظمة حاسوب & 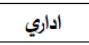 \\
\hline 10 & 4 & 4 & 5 & 5 & 2 & 5 & 4 & 5 & 4 & 4 & 1 & 4 & 5 & 4 & 2 & 4 & 4 & 1 & 3 & 3 & أنظمة حاسوب | & اداري ل ادي \\
\hline 11 & 4 & 4 & 5 & 5 & 2 & 5 & 4 & 5 & 4 & 4 & 1 & 4 & 5 & 4 & 2 & 4 & 4 & 1 & 3 & 3 & |أنظمة حاسوب | & الداري \\
\hline 12 & 4 & 4 & 5 & 5 & 2 & 5 & 4 & 5 & 4 & - & 1 & 4 & 5 & 4 & 2 & 2 & 2 & 2 & - & 2 & أنظطة حاسوب & 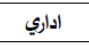 \\
\hline 13 & 3 & 3 & 5 & 3 & 3 & 5 & 3 & 5 & 5 & 5 & 5 & 5 & 5 & 3 & 2 & 5 & 1 & 3 & 3 & 5 & |أنظة حاسوب & الداري ل إي \\
\hline 14 & 5 & 3 & 5 & 3 & 3 & 5 & 3 & 5 & 5 & 5 & 5 & 5 & $\sigma$ & 3 & 2 & 5 & 1 & 3 & 3 & 5 & | أنظة حاسوب & اداري \\
\hline 15 & 3 & 3 & 5 & 3 & 3 & 5 & 3 & 5 & 5 & 5 & 5 & 5 & 5 & 3 & 2 & 5 & 1 & 3 & 3 & 5 & |أنظمة حاسوب | & اداري \\
\hline 16 & 3 & 2 & 4 & 3 & 4 & 3 & 2 & 4 & 3 & 3 & 2 & 3 & 3 & 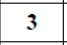 & 3 & 3 & 3 & 3 & 3 & 3 & | أنظمة حاسوب & الداري ل إي \\
\hline 17 & 4 & 3 & 4 & 4 & 4 & 3 & 4 & 5 & 5 & 5 & 4 & 4 & 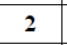 & 4 & 5 & 4 & 5 & 5 & 3 & 5 & |أنظمة حاسوب & اداري ل ادي \\
\hline 18 & 4 & 4 & 5 & 4 & 5 & 5 & 3 & 4 & 3 & 4 & 4 & 3 & 4 & 4 & 3 & 3 & 3 & 5 & 5 & 4 & | أنظمة حاسوب & اداري \\
\hline 19 & 4 & 1 & 4 & 4 & 4 & 4 & 4 & 4 & 4 & 4 & 4 & 4 & 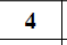 & 4 & 4 & 4 & 2 & 4 & 4 & 4 & | أنظمة حاسوب & اداري \\
\hline 20 & 4 & 2 & 4 & 4 & 3 & 4 & 4 & 4 & 4 & 4 & 4 & 3 & 4 & 4 & 3 & 3 & 3 & 4 & 4 & 3 & |أنظطة حاسوب | & الداري \\
\hline 21 & 4 & 2 & 4 & 4 & 3 & 4 & 4 & 4 & 4 & 4 & 4 & 3 & 4 & 4 & 3 & 3 & 3 & 4 & 4 & 3 & | أنظمة حاسوب & اداري ل ادي \\
\hline 22 & 4 & 2 & 4 & 4 & 3 & 4 & 4 & 4 & 4 & 4 & 4 & 3 & 4 & 4 & 3 & 3 & 3 & 4 & 4 & 4 & | أنظمة حاسوب & اداري \\
\hline 23 & 4 & 4 & 4 & 4 & 4 & 2 & 4 & 4 & 4 & 4 & 4 & 2 & 2 & 2 & 2 & 4 & 2 & 4 & 4 & 4 & أنظمة حاسوب & الداري \\
\hline 24 & 3 & 5 & 3 & 2 & 5 & 5 & 3 & 5 & 3 & 3 & 1 & 5 & 4 & 2 & 4 & 5 & 5 & 5 & 3 & 5 & | أنظمة حاسوب & الداري ل ل إي \\
\hline 25 & 5 & 5 & 3 & 2 & 5 & 1 & 5 & 5 & 5 & 5 & 4 & 5 & 4 & 5 & 3 & 4 & 5 & 5 & 5 & 5 & | أنظة حاسوب & اداري ل ادي \\
\hline 26 & 3 & 2 & 4 & 4 & 4 & 3 & 2 & 1 & 3 & 3 & 3 & 4 & 4 & 1 & 2 & 2 & 3 & 3 & 3 & 4 & أنظمة حاسوب | & اداري \\
\hline 27 & 2 & 2 & 5 & 2 & 1 & 1 & 3 & 3 & 2 & 3 & 4 & 5 & 4 & 9 & 2 & 1 & 3 & 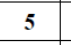 & 3 & 1 & | أنظمة حاسوب & 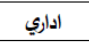 \\
\hline 28 & 4 & 3 & 5 & 4 & 3 & 3 & 4 & 5 & 4 & 4 & 4 & 5 & 2 & 4 & 5 & 4 & 4 & 4 & 4 & 5 & | أنظمة حاسوب & اداري ل ل ادي \\
\hline 29 & 4 & 3 & 5 & 4 & 3 & 3 & 4 & 5 & 4 & 4 & 4 & 5 & 2 & 4 & 5 & 4 & 4 & 4 & 4 & 5 & | أنظمة حاسوب & اداري ل ل ادي \\
\hline 30 & 4 & 4 & 4 & 4 & 4 & 4 & 4 & 4 & 3 & 4 & 3 & 5 & 3 & 4 & 5 & 4 & 2 & 4 & 3 & 3 & أنظطة حاسو. & اددري \\
\hline 31 & 4 & 4 & 4 & 4 & 4 & 4 & 3 & 4 & 3 & 4 & 3 & 5 & 3 & 4 & 5 & 4 & 2 & 1 & 3 & 3 & أنظمة حاسوب & اداري \\
\hline 32 & 4 & 4 & 4 & 2 & 5 & 5 & 5 & 4 & 5 & 4 & 3 & 4 & 3 & 2 & 1 & 5 & 5 & 5 & 3 & 5 & |أنظمة حاسوب & اداري \\
\hline 33 & 4 & 1 & 5 & 4 & 1 & 2 & 5 & 2 & 5 & 4 & 2 & 3 & 5 & 5 & 3 & 3 & 3 & 1 & 5 & 3 & أنظة حاسوب & اداري \\
\hline 34 & 4 & 4 & 5 & 2 & 5 & 5 & 5 & 4 & 5 & 4 & 3 & 4 & 3 & 2 & 1 & 5 & 5 & 5 & 3 & 5 & أنظمة حاسوو & اداري \\
\hline 35 & 4 & 4 & 1 & 2 & 5 & 5 & 5 & 4 & 5 & 4 & 3 & 4 & 3 & 2 & 1 & 5 & 5 & 5 & 3 & 5 & |أنظمة حاسوب & الداري \\
\hline 36 & 5 & 2 & 5 & 4 & 4 & 1 & 5 & 5 & 4 & 5 & 1 & 5 & 5 & 1 & 4 & 5 & 5 & 5 & 5 & 4 & أنظمة حاسوو & اداري \\
\hline 37 & 5 & 2 & 5 & 4 & 4 & 1 & 5 & 5 & 4 & 5 & 2 & 5 & 5 & 1 & 4 & 5 & 5 & 5 & 5 & 4 & أنظة حاسوب & اداري \\
\hline 38 & 3 & 4 & 4 & 5 & 4 & 5 & 5 & 5 & 5 & 4 & 3 & 4 & 3 & 3 & 3 & 4 & 5 & 3 & 4 & 4 & أنظمة حاسوب & الداري \\
\hline 39 & 4 & 2 & 4 & 4 & 4 & 4 & 4 & 4 & 4 & 4 & 4 & 4 & 4 & 4 & 4 & 4 & 4 & 4 & 4 & 5 & أنظمة حاسوب & الداري \\
\hline 40 & 3 & 4 & 1 & 3 & 2 & 4 & 1 & 1 & 2 & 3 & 3 & 4 & 3 & 3 & 4 & 2 & 3 & 1 & 1 & 4 & |أنظة حاسوب & اداري \\
\hline 41 & 4 & 4 & 4 & 2 & 2 & 2 & 4 & 2 & 2 & 2 & 2 & 2 & 4 & 4 & 4 & 2 & 2 & 2 & 4 & 3 & أنظمة حاسوب & اداري \\
\hline 42 & 5 & 2 & 3 & 3 & 4 & 1 & 5 & 3 & 4 & 5 & 4 & 5 & 4 & 5 & 4 & 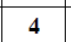 & 2 & 1 & 4 & 5 & | أنظة حاسوب & اداري \\
\hline 43 & 4 & 4 & 5 & 5 & 4 & 1 & 5 & 1 & 4 & 5 & 4 & 4 & 5 & 4 & 5 & 3 & 2 & 3 & 4 & 3 & أنظطة حاسوي & الداري \\
\hline 44 & 4 & 1 & 5 & 4 & 4 & 2 & 5 & 5 & 1 & 4 & 3 & 4 & 4 & 3 & 1 & 5 & 3 & 2 & 4 & 5 & |أنظة حاسوب & اداري \\
\hline 45 & 4 & 4 & 5 & 4 & 4 & 4 & 4 & 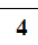 & 2 & 4 & 5 & 2 & 4 & 4 & 4 & 4 & 5 & - & 5 & 4 & |أنظة حاسوب & اداري \\
\hline 46 & 4 & 4 & 5 & 4 & 4 & 4 & 4 & 4 & 2 & 4 & 5 & 2 & 4 & 4 & 1 & 4 & 5 & 5 & 5 & 4 & أنظمة حاسوب & ادادري \\
\hline No & $\mathrm{x} 1$ & $\mathrm{x} 2$ & $\times 3$ & $\mathrm{x4}$ & $\times 5$ & $\times 6$ & $x 7$ & $x 8$ & $\times 9$ & $x 10$ & $\mathrm{x} 11$ & x12 & $\mathrm{x} 13$ & \begin{tabular}{|l|}
$x 14$ \\
\end{tabular} & $\mathrm{x} 15$ & x16 & \begin{tabular}{|l|}
$x 17$ \\
\end{tabular} & \begin{tabular}{|l|l|}
$x 18$ \\
\end{tabular} & \begin{tabular}{|l|}
$x 19$ \\
\end{tabular} & $\mathrm{x} 20$ & الفم العلمي & التخصص \\
\hline 47 & 1 & 4 & 3 & 5 & 4 & 2 & 3 & 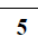 & 5 & 5 & 5 & 5 & 5 & 5 & 4 & 4 & 2 & 4 & 3 & 4 & أنظة حاسوب & اداري \\
\hline 48 & 3 & 3 & 4 & 4 & 4 & 2 & 4 & 5 & 5 & 4 & 4 & 5 & 4 & 4 & 8 & 4 & 2 & 4 & 4 & 4 & أنظمة حاسوب & اداري \\
\hline 49 & 1 & 5 & 5 & $J$ & 4 & 2 & 4 & 4 & 4 & 4 & 3 & 4 & & 4 & 4 & 4 & 2 & 4 & 5 & 5 & |أنظة حاسوب & اداري \\
\hline
\end{tabular}




\begin{tabular}{|c|c|c|c|c|c|c|c|c|c|c|c|c|c|c|c|c|c|c|c|c|c|c|}
\hline 50 & 4 & 4 & 4 & 4 & 4 & 3 & 5 & 5 & 4 & 5 & 3 & 5 & 4 & 4 & 5 & 4 & 2 & 1 & 4 & 2 & أنظمة حاسوب & اداري \\
\hline 51 & 1 & 5 & 5 & 5 & 4 & 2 & 4 & 4 & 4 & 4 & 3 & 4 & 4 & 4 & 4 & 4 & 5 & 4 & 4 & 4 & أنظمة حاسوب & اداري \\
\hline 52 & 3 & 4 & 4 & 4 & 4 & 3 & 4 & 4 & 4 & 4 & 4 & 4 & 4 & 4 & 4 & 3 & 3 & 4 & 3 & 4 & أنظمة حاسوب & اداري \\
\hline 53 & 1 & 5 & 5 & 5 & 4 & 2 & 4 & 4 & 4 & 3 & 4 & 4 & 4 & 4 & 4 & 4 & 2 & 4 & 4 & 4 & أنظمة حاسوب & اداري \\
\hline 54 & 4 & 2 & 4 & 4 & 5 & 1 & 5 & 4 & 4 & 4 & 4 & 5 & 5 & 5 & 5 & 5 & 2 & 4 & 5 & 5 & أنظمة حاسوب & اداري \\
\hline 55 & 3 & 4 & 4 & 4 & 4 & 3 & 4 & 4 & 4 & 3 & 3 & 4 & 4 & 3 & 4 & 3 & 4 & 3 & 3 & 3 & أنظمة حاسوب & اداري \\
\hline 56 & 1 & 5 & 5 & 5 & 4 & 2 & 4 & 4 & 3 & 3 & 4 & 4 & 5 & 5 & 3 & 4 & 2 & 4 & 3 & 4 & أنظمة حاسوب & اداري \\
\hline 57 & 4 & 4 & 4 & 4 & 4 & 4 & 3 & 4 & 3 & 4 & 3 & 5 & 3 & 4 & 5 & 4 & 2 & 4 & 3 & 3 & أنظمة حاسوب & اداري \\
\hline 58 & 1 & 1 & 2 & 5 & 4 & 2 & 1 & 5 & 1 & 4 & 5 & 1 & 5 & 4 & 5 & 2 & 5 & 4 & 5 & 4 & أنظمة حاسوب & اداري \\
\hline 59 & 4 & 1 & 4 & 5 & 4 & 1 & 5 & 5 & 5 & 5 & 5 & 5 & 5 & 4 & 5 & 4 & 1 & 4 & 5 & 4 & أنظمة حاسوب & اداري \\
\hline 60 & 4 & 3 & 2 & 4 & 4 & 4 & 4 & 4 & 3 & 4 & 4 & 5 & 4 & 2 & 4 & 3 & 4 & 4 & 5 & 4 & أنظمة حاسوب & اداري \\
\hline 61 & 2 & 4 & 2 & 2 & 2 & 4 & 5 & 5 & 4 & 5 & 5 & 4 & 5 & 5 & 4 & 4 & 1 & 5 & 2 & 4 & أنظمة حاسوب & ادراي \\
\hline 62 & 4 & 2 & 4 & 4 & 5 & 4 & 2 & 5 & 5 & 3 & 3 & 2 & 3 & 3 & 3 & 5 & 2 & 5 & 4 & 4 & إدارة اعمال & الإداري \\
\hline 63 & 4 & 2 & 5 & 4 & 5 & 4 & 4 & 4 & 4 & 5 & 5 & 4 & 4 & 4 & 5 & 2 & 4 & 3 & 5 & 4 & إدارة اعمال & الإداري \\
\hline 64 & 5 & 5 & 5 & 5 & 5 & 5 & 4 & 5 & 4 & 4 & 5 & 5 & 5 & 4 & 5 & 4 & 1 & 5 & 5 & 5 & إدارة المواد & الإداري \\
\hline 65 & 3 & 4 & 5 & 1 & 4 & 1 & 5 & 1 & 1 & 5 & 4 & 3 & 2 & 1 & 5 & 5 & 3 & 1 & 3 & 5 & إدارة المواد & الإداري \\
\hline 66 & 2 & 4 & 5 & 4 & 4 & 3 & 4 & 3 & 4 & 3 & 3 & 5 & 4 & 4 & 5 & 3 & 4 & 3 & 4 & 5 & إدارة المواد & الإداري \\
\hline 67 & 4 & 2 & 2 & 4 & 1 & 5 & 3 & 4 & 3 & 4 & 4 & 3 & 2 & 4 & 3 & 4 & 4 & 3 & 4 & 3 & إدارة المواد & الإداري \\
\hline 68 & 5 & 1 & 5 & 5 & 5 & 2 & 3 & 5 & 5 & 5 & 5 & 5 & 5 & 5 & 5 & 5 & 5 & 5 & 4 & 5 & إدارة المواد & الإداري \\
\hline 69 & 1 & 5 & 4 & 4 & 4 & 5 & 4 & 4 & 4 & 4 & 4 & 4 & 4 & 1 & 4 & 1 & 5 & 1 & 5 & 5 & إدارة المواد & الإداري \\
\hline 70 & 4 & 4 & 4 & 4 & 4 & 4 & 4 & 4 & 4 & 4 & 4 & 4 & 4 & 3 & 3 & 4 & 2 & 4 & 5 & 5 & إدارة المواد & الإداري \\
\hline 71 & 3 & 4 & 5 & 5 & 3 & 4 & 4 & 5 & 4 & 5 & 5 & 4 & 3 & 4 & 3 & 4 & 5 & 5 & 2 & 3 & إدارة المواد & الإداري \\
\hline 72 & 4 & 3 & 4 & 4 & 2 & 2 & 3 & 2 & 3 & 3 & 4 & 4 & 5 & 1 & 2 & 3 & 1 & 4 & 2 & 3 & إدارة المواد & الإداري \\
\hline 73 & 4 & 2 & 4 & 4 & 4 & 2 & 4 & 4 & 2 & 4 & 4 & 2 & 4 & 4 & 4 & 4 & 2 & 2 & 4 & 4 & إدارة المواد & الإداري \\
\hline 74 & 4 & 4 & 5 & 4 & 4 & 5 & 4 & 5 & 5 & 4 & 3 & 4 & 4 & 3 & 5 & 3 & 3 & 1 & 4 & 3 & إدارة المواد & الإداري \\
\hline 75 & 4 & 5 & 5 & 4 & 2 & 4 & 3 & 4 & 1 & 4 & 5 & 2 & 3 & 4 & 5 & 4 & 5 & 4 & 4 & 3 & إدارة المواد & الإداري \\
\hline 76 & 5 & 2 & 5 & 5 & 5 & 4 & 4 & 5 & 5 & 5 & 5 & 5 & 4 & 4 & 4 & 4 & 2 & 4 & 5 & 4 & إدارة المواد & الإداري \\
\hline 77 & 5 & 5 & 5 & 4 & 5 & 4 & 5 & 3 & 2 & 4 & 5 & 3 & 5 & 3 & 5 & 5 & 1 & 5 & 3 & 3 & إدارة المواد & الإداري \\
\hline 78 & 3 & 3 & 3 & 3 & 3 & 3 & 3 & 3 & 3 & 3 & 3 & 5 & 5 & 5 & 5 & 5 & 1 & 5 & 5 & 5 & إدارة المواد & الإداري \\
\hline 79 & 4 & 4 & 4 & 4 & 4 & 2 & 4 & 4 & 5 & 4 & 5 & 5 & 4 & 5 & 4 & 3 & 3 & 5 & 4 & 3 & إدارة المواد & الإداري \\
\hline 80 & 5 & 3 & 5 & 5 & 4 & 5 & 5 & 5 & 5 & 4 & 4 & 5 & 4 & 3 & 5 & 5 & 5 & 1 & 5 & 5 & إدارة المواد & الإداري \\
\hline 81 & 4 & 1 & 5 & 4 & 3 & 2 & 5 & 4 & 4 & 5 & 4 & 5 & 3 & 3 & 4 & 4 & 5 & 3 & 4 & 4 & إدارة المواد & الإداري \\
\hline 82 & 4 & 2 & 4 & 3 & 3 & 2 & 1 & 3 & 4 & 3 & 3 & 1 & 4 & 3 & 3 & 3 & 2 & 5 & 5 & 4 & إدارة المواد & الإداري \\
\hline 83 & 5 & 1 & 5 & 5 & 1 & 3 & 4 & 4 & 2 & 5 & 2 & 4 & 3 & 5 & 2 & 4 & 2 & 1 & 4 & 4 & إدارة المواد & الإداري \\
\hline 84 & 4 & 4 & 5 & 5 & 2 & 5 & 4 & 5 & 4 & 4 & 1 & 4 & 5 & 4 & 2 & 4 & 4 & 1 & 3 & 2 & كهرباء & تكنلوجي \\
\hline 85 & 3 & 1 & 5 & 5 & 5 & 5 & 4 & 5 & 5 & 5 & 2 & 5 & 3 & 5 & 5 & 5 & 1 & 4 & 4 & 4 & كهرباء & تكنلوجي \\
\hline 86 & 3 & 4 & 4 & 5 & 4 & 3 & 4 & 5 & 4 & 5 & 4 & 5 & 4 & 3 & 5 & 4 & 5 & 4 & 2 & 5 & كهرباء & تكنلوجي \\
\hline 87 & 4 & 4 & 4 & 4 & 4 & 2 & 4 & 2 & 4 & 4 & 4 & 2 & 4 & 2 & 4 & 2 & 4 & 2 & 2 & 2 & كهرباء & تكنلوجي \\
\hline 88 & 4 & 2 & 4 & 4 & 4 & 2 & 4 & 4 & 4 & 4 & 4 & 4 & 4 & 4 & 4 & 4 & 2 & 4 & 4 & 4 & كهرباء & تكنلوجي \\
\hline 89 & 3 & 5 & 2 & 4 & 1 & 5 & 4 & 4 & 5 & 5 & 4 & 5 & 1 & 4 & 5 & 4 & 3 & 5 & 3 & 4 & كهرباء & تكنلوجي \\
\hline 90 & 4 & 4 & 4 & 3 & 1 & 4 & 5 & 5 & 4 & 4 & 2 & 3 & 4 & 3 & 4 & 4 & 4 & 2 & 2 & 4 & كهرباء & تكنلوجي \\
\hline 91 & 4 & 3 & 5 & 4 & 5 & 5 & 4 & 4 & 4 & 5 & 5 & 4 & 4 & 4 & 4 & 4 & 2 & 4 & 4 & 4 & كهرباء & تكنلوجي \\
\hline 92 & 4 & 1 & 4 & 4 & 1 & 5 & 2 & 4 & 1 & 1 & 4 & 5 & 5 & 5 & 2 & 5 & 4 & 3 & 4 & 5 & كهرباء & تكنلوجي \\
\hline 93 & 1 & 5 & 5 & 3 & 3 & 5 & 5 & 5 & 5 & 5 & 4 & 4 & 3 & 3 & 5 & 3 & 3 & 4 & 4 & 4 & كهرباء & تكنلوجي \\
\hline No & $\mathrm{x} 1$ & $\times 2$ & $x 3$ & $\mathrm{x4}$ & $\times 5$ & $x 6$ & $\times 7$ & $x 8$ & x9 & $\mathrm{x} 10$ & $\mathrm{x} 11$ & $\mathrm{x} 12$ & $\mathrm{x} 13$ & $\mathrm{x} 14$ & $\mathrm{x} 15$ & $\mathrm{x} 16$ & $\mathrm{x} 17$ & $\mathrm{x} 18$ & $\mathrm{x} 19$ & $\times 20$ & الفسم العلمي & التخصص \\
\hline 94 & 1 & 2 & 3 & 4 & 4 & 3 & 5 & 4 & 3 & 2 & 1 & 4 & 5 & 2 & 3 & 4 & 1 & 2 & 5 & 3 & كهرباء & تكنلوجي \\
\hline 95 & 4 & 4 & 5 & 5 & 4 & 5 & 3 & 3 & 5 & 4 & 3 & 4 & 3 & 4 & 5 & 4 & 3 & 4 & 4 & 5 & كهرباء & تكنلوجي \\
\hline 96 & 4 & 1 & 5 & 5 & 4 & 5 & 4 & 5 & 5 & 4 & 1 & 5 & 5 & 4 & 4 & 4 & 1 & 5 & 5 & 4 & كهرباء & تكنلوجي \\
\hline
\end{tabular}




\begin{tabular}{|c|c|c|c|c|c|c|c|c|c|c|c|c|c|c|c|c|c|c|c|c|c|c|}
\hline 97 & 4 & 5 & 5 & 4 & 4 & 5 & 4 & 5 & 5 & 4 & 3 & 5 & 3 & 2 & 4 & 5 & 4 & 5 & 4 & 3 & كهرباء & تكنلوجي \\
\hline 98 & 1 & 5 & 5 & 5 & 5 & 5 & 5 & 5 & 5 & 5 & 4 & 5 & 5 & 4 & 3 & 5 & 5 & 5 & 4 & 5 & كهباء & تكنلوجي \\
\hline 99 & 4 & 1 & 4 & 5 & 5 & 5 & 4 & 5 & 5 & 4 & 1 & 5 & 1 & 5 & 4 & 5 & 5 & 1 & 4 & 5 & كهرباء & تكلنوجي \\
\hline 100 & 1 & 5 & 5 & 5 & 5 & 3 & 5 & 5 & 4 & 3 & 3 & 3 & 4 & 4 & 3 & 5 & 5 & 3 & 4 & 4 & كهباء & تكنلوجي \\
\hline 101 & 1 & 5 & 5 & 5 & 5 & 1 & 5 & 4 & 3 & 3 & 3 & 4 & 3 & 4 & 3 & 5 & 5 & 3 & 5 & 4 & كهرباء & تكلنوجي \\
\hline 102 & 4 & 2 & 5 & 4 & 4 & 3 & 4 & 4 & 4 & 4 & 4 & 4 & 4 & 4 & 4 & 4 & 2 & 5 & 5 & 4 & كهرباء & تكلنوجي \\
\hline 103 & 4 & 2 & 5 & 3 & 3 & 5 & 5 & 5 & 3 & 3 & 4 & 3 & 5 & 1 & 5 & 3 & 3 & 5 & 5 & 5 & كهرباء & تكنلوجي \\
\hline 104 & 4 & 2 & 5 & 3 & 3 & 5 & 5 & 5 & 3 & 2 & 3 & 3 & 4 & 5 & 5 & 3 & 4 & 5 & 5 & 5 & كهرباء & تكنلوجي \\
\hline 105 & 3 & 1 & 4 & 3 & 5 & 3 & 4 & 4 & 5 & 4 & 3 & 4 & 3 & 2 & 3 & 3 & 2 & 3 & 4 & 5 & كهباء & تكلنوجي \\
\hline 106 & 4 & 2 & 4 & 5 & 4 & 3 & 5 & 4 & 2 & 4 & 5 & 4 & 2 & 1 & 4 & 5 & 2 & 5 & 2 & 4 & كهرباء & تكلنوجي \\
\hline 107 & 5 & 4 & 5 & 5 & 4 & 3 & 4 & 5 & 5 & 5 & 3 & 5 & 5 & 3 & 5 & 5 & 2 & 1 & 1 & 3 & كهرباء & شبكات \\
\hline 108 & 5 & 4 & 5 & 5 & 4 & 3 & 4 & 5 & 5 & 5 & 3 & 5 & 5 & 3 & 3 & 5 & 1 & 5 & 5 & 3 & كهرباء & شبكات \\
\hline 109 & 5 & 5 & 5 & 5 & 5 & 5 & 5 & 5 & 5 & 5 & 5 & 5 & 1 & 5 & 5 & 3 & 3 & 1 & 4 & 4 & كهباء & شبكات \\
\hline 110 & 4 & 4 & 4 & 4 & 4 & 4 & 2 & 5 & 4 & 2 & 5 & 4 & 4 & 5 & 4 & 2 & 5 & 5 & 4 & 5 & تحليلات مرضية & طبي \\
\hline 111 & 5 & 4 & 1 & 3 & 5 & 3 & 4 & 3 & 3 & 3 & 5 & 4 & 3 & 3 & 3 & 3 & 3 & 3 & 4 & 5 & تحليلات مرضية & طبي \\
\hline 112 & 4 & 5 & 4 & 5 & 3 & 2 & 5 & 5 & 5 & 4 & 2 & 5 & 2 & 4 & 4 & 4 & 5 & 2 & 2 & 4 & تحليلات مرضية & طبي \\
\hline 113 & 4 & 1 & 4 & 5 & 5 & 5 & 5 & 5 & 5 & 5 & 1 & 4 & 1 & 1 & 5 & 4 & 5 & 2 & 4 & 4 & تحليلات مرضية & طبي \\
\hline 114 & 4 & 4 & 4 & 4 & 4 & 2 & 4 & 4 & 4 & 4 & 4 & 4 & 2 & 2 & 4 & 4 & 4 & 2 & 2 & 2 & تحليلات مرضية & طبي \\
\hline 115 & 4 & 2 & 4 & 4 & 3 & 4 & 4 & 4 & 4 & 4 & 5 & 4 & 4 & 4 & 4 & 4 & 2 & 4 & 5 & 5 & تحليلات مرضية & طبي \\
\hline
\end{tabular}

